\title{
MEASURING LOCALIZATION IN THE AGE OF ECONOMIC GLOBALIZATION
}

Kristina V. Baris, Ma. Charmaine R. Crisostomo, Krizia Anne V. Garay, Christian Regie J. Jabagat, Mahinthan J. Mariasingham, and Elyssa Mariel T. Mores

NO. 647

February 2022
ADB ECONOMICS WORKING PAPER SERIES 


\section{ADB Economics Working Paper Series}

\section{Measuring Localization in the Age of Economic Globalization}

Kristina V. Baris, Ma. Charmaine R. Crisostomo, Krizia Anne V. Garay, Christian Regie J. Jabagat, Mahinthan J. Mariasingham, and Elyssa Mariel T. Mores

No. 647 | February 2022
Kristina V. Baris (baris.istin@gmail.com), Ma. Charmaine R. Crisostomo (mccrisostomo.consultant@adb.org), Krizia Anne V. Garay (krizia.garay@gmail.com),

Christian Regie J. Jabagat (cjabagat.consultant@adb.org), and Elyssa Mariel T. Mores (emores.consultant@adb.org) are consultants and Mahinthan J. Mariasingham (mmariasingham@adb.org) is a senior statistician at the Economic Research and Regional Cooperation Department, Asian Development Bank. 
(C) 2022 Asian Development Bank 6 ADB Avenue, Mandaluyong City, 1550 Metro Manila, Philippines

Tel +632 8632 4444; Fax +63286362444

www.adb.org

Some rights reserved. Published in 2022.

ISSN 2313-6537 (print), 2313-6545 (electronic)

Publication Stock No. WPS220038-2

DOI: http://dx.doi.org/10.22617/WPS220038-2

The views expressed in this publication are those of the authors and do not necessarily reflect the views and policies of the Asian Development Bank (ADB) or its Board of Governors or the governments they represent.

ADB does not guarantee the accuracy of the data included in this publication and accepts no responsibility for any consequence of their use. The mention of specific companies or products of manufacturers does not imply that they are endorsed or recommended by ADB in preference to others of a similar nature that are not mentioned.

By making any designation of or reference to a particular territory or geographic area, or by using the term "country" in this document, $A D B$ does not intend to make any judgments as to the legal or other status of any territory or area.

This work is available under the Creative Commons Attribution 3.0 IGO license (CC BY 3.0 IGO)

https://creativecommons.org/licenses/by/3.0/igo/. By using the content of this publication, you agree to be bound by the terms of this license. For attribution, translations, adaptations, and permissions, please read the provisions and terms of use at https://www.adb.org/terms-use\#openaccess.

This CC license does not apply to non-ADB copyright materials in this publication. If the material is attributed to another source, please contact the copyright owner or publisher of that source for permission to reproduce it. $\mathrm{ADB}$ cannot be held liable for any claims that arise as a result of your use of the material.

Please contact pubsmarketing@adb.org if you have questions or comments with respect to content, or if you wish to obtain copyright permission for your intended use that does not fall within these terms, or for permission to use the ADB logo.

Corrigenda to ADB publications may be found at http://www.adb.org/publications/corrigenda.

Notes:

In this publication, "\$” refers to United States dollars.

ADB recognizes "China" as the People's Republic of China.

The ADB Economics Working Paper Series presents data, information, and/or findings from ongoing research and studies to encourage exchange of ideas and to elicit comment and feedback about development issues in Asia and the Pacific. Since papers in this series are intended for quick and easy dissemination, the content may or may not be fully edited and may later be modified for final publication. 


\section{CONTENTS}

TABLES AND FIGURES iv

ABSTRACT V v v v v v v v v

$\begin{array}{lll}\text { I. INTRODUCTION } & 1\end{array}$

II. MEASURING AGGLOMERATION

A. $\quad$ Constructing the Index 4

B. Data 7

C. Agglomeration and Global Value Chains 7

III. CAPTURING CONCENTRATION OF ACTIVITIES WITHIN 12 THE DOMESTIC SECTORS

A. Constructing the Adjusted Agglomeration Index $\quad 12$

B. Base versus Adjusted Agglomeration 13

IV. COMPARING AGGLOMERATION WITH EXISTING INDEXES 16

A. Correlations 16

$\begin{array}{ll}\text { B. Year Trends } & 18\end{array}$

V. CONCLUSIONS $\quad 21$

$\begin{array}{ll}\text { APPENDIXES } & 23\end{array}$

$\begin{array}{lr}\text { REFERENCES } & 29\end{array}$ 


\section{TABLES AND FIGURES}

\section{TABLES}

A1 Sector Descriptions of the ADB Multiregional Input-Output Table 24

A2.1 Regression Results using Backward Agglomeration 25

A2.2 Regression Results using Forward Agglomeration 26

\section{FIGURES}

1 The Agglomeration Map $\quad 7$

2 Economy-Level Trends in Agglomeration, Selected Years 8

3 Agglomeration Trends for the Light Manufacturing Sectors, Selected Years 9

4 Sensitivity of Agglomeration and Global Value Chain Participation 11

5 Changes in Agglomeration Class, 2007 and 2019

6 Sector-Level Changes in Agglomeration of Nepal, 2019

7 Scatterplots of Backward Agglomeration and Reshoring Indexes, 2012 and 2019

$8 \quad$ Scatterplots of Forward Agglomeration and Reshoring Indexes, 2012 and 2019

9 Year Trends for the Indexes, 2007-2020 19

10 Top Five Economies Using the Backward Agglomeration Index, 2007-2020 20

11 Top Five Economies Using the Forward Agglomeration Index, 2007-2020 21

A1 The ADB Multiregional Input-Output Table Structure 23 


\begin{abstract}
In a highly integrated global economy, linkages of domestic sectors to global trade measure an economy's ability to gain from participating in global value chains. On the other hand, the strength of domestic linkages can provide insights on an economy's cross-industry trade and extent of the localization of economic activity. This paper proposes a measure of domestic linkages based on a value added approach. Using the Asian Development Bank's multiregional input-output table from 2000 and 2007 to 2020, this paper estimates a backward agglomeration index, which measures the extent to which different sectors in the economy source value added from domestic sectors for domestic consumption. An analogous forward agglomeration index, which measures the extent to which domestic sectors absorb value added, is also defined. The combinations of backward and forward agglomeration indexes are consequently used to analyze an economy or a sector's agglomeration status. The agglomeration indexes show a positive correlation with existing reshoring indexes, and a negative correlation with global value chain participation. The indexes are further extended to account for distribution of activities within domestic sectors.
\end{abstract}

Keywords: agglomeration, value added, globalization, multiregional input-output table, global value chains

JEL codes: D24, D57, F15, O14 


\section{INTRODUCTION}

In economic geography, spatial agglomeration refers to the concentration of industries in a specific location. A widely documented example of spatial agglomeration is the case of the United States (US), where electronics industries cluster in Silicon Valley, pharmaceutical industries in New York, and textile and apparel in North and South Carolina. In Asia, spatial agglomeration of industries, especially in the People's Republic of China (PRC) and other East Asian economies, can also be observed. In the PRC, industries such as information and software services, financial services, real estate and leasing, business services, and scientific research and technical services agglomerate in the Beijing-Tianjin-Heibei region. Meanwhile, manufacturing, construction, financial services, and leasing and business services agglomerate in the Yangtze River Delta led by Shanghai, and manufacturing activities aggregate in the Pearl River Delta (Han et al. 2019). Applying the concept of clustering at a global context, this paper defines localization as the transfer of activities previously performed externally back to the domestic economy. Concentration of localization activities, or clustering of activities domestically, is defined as agglomeration.

The economic forces facilitating agglomeration are not directly linked to the theory of comparative advantage; hence, attempts of explaining localization forces have been made to fill in this gap in the theory. In 1890, Marshall identified four motivations of industry agglomeration from the point of view of the economy of production. The first and most obvious motivation is the physical condition or the natural advantages of the location such as the climate, soil condition, and existence and abundance of natural resources relevant to the industry. In today's context, this may be modified to include regulatory environment. The second alludes to positive externalities, especially industry-knowledge spillovers that are made possible through spatial agglomeration when, in Marshall's (1920) words, “... one man starts a new idea, it is taken up by others and combined with suggestions of their own; and thus, it becomes the source of further new ideas." The third refers to the industry gains from labor market pooling, where agglomerated industries attract skilled labor relevant to the production.

The fourth force relates to demand for intermediate goods of existing industries. Clustering of firms in a downstream industry will create demand for intermediate goods from more upstream industries, thus creating incentives for firms in the upstream industry to move their production to a closer location. However, Venables (1996) cautions that this localization force will only take effect whenever there are some barriers to trade, such as transportation cost of the intermediate goods to the downstream industry; otherwise, there is no incentive for upstream firms to relocate. In a simple model explored in Venables (1996) and Krugman and Venables (1996), where intermediate goods production and consumption create cost and demand linkages among firms, spatial agglomeration dominates in areas with low trade barriers.

Apart from increased demand for intermediate goods, Krugman and Venables (1996) discuss another benefit of agglomeration. Economies with agglomerated industries would fare better against an industry-specific demand shock than an economy with a smaller production of the same industry. Decline in output is likely to be larger for the economy where there is a smaller scale of production. While benefits of agglomerating are plenty, there are downsides. With an agglomerated economy, it is possible that when a production technology becomes obsolete and more efficient production technology is invented elsewhere, the economy with agglomerated industry has bigger sunk costs that may severely delay its adoption of the new technology. Meanwhile, an economy with the smaller and less agglomerated production can redistribute its factors of production easier to adopt the new technology. 
The implications may also hold true for the concept of agglomeration explored in this paper, which revolves around global value chains (GVCs). Highly agglomerated economies in the context of GVCs may have strong domestic upstream industries. Because downstream industries rely on domestic sectors as a source of inputs, they are less vulnerable to industry-specific shocks present in a highly globalized economy.

This paper adopts the concept of agglomeration in the context of GVCs. In the last 2 decades, GVCs have gained significant importance in trade and production. It has allowed for production processes to be fragmented and shared across economies, giving rise to a highly interconnected global economy. The shift from hyperglobalization, a period of expansion in trade of intermediates, to "slowbalization," characterized by a decline in global trade, affects economies across the globe.

In this context, the role and strength of domestic linkages through intermediate goods has never been more important. A highly integrated global economy implies that different economies are vulnerable to supply chain risks, which can offset benefits of fragmenting production processes based on cost-related factors (Giuseppina and Michele 2018). In addition, maximizing gains from participating in GVCs relies on the ability of domestic sectors to gain value added from these activities (Koopman, Wang, and Wei 2008). Domestic activities indirectly associated with GVC activities, such as production of intermediate goods that are later exported, provide a picture of GVCs not typically captured in the literature (Mercer-Blackman, Foronda, and Mariasingham 2017). With these considerations, this paper adopts the concept of agglomeration by looking at different economies' decisions to "locate" activities domestically. We explore the clustering of economic activities in domestic sectors in the midst of a highly interconnected global economy by developing an index that measures the strength of an economy's domestic linkages.

Several studies attempted to capture domestic linkages in the context of global trade. Jones (2011) made a significant contribution to this end by recognizing intermediate goods as a form of capital used in production, and that these goods create a similar multiplier effect that capital has in a neoclassical growth model. In the analytical model with conventional parameterization laid in his paper, a doubling of total factor productivity increases output by a factor of 8.0 when intermediate goods multiplier is present, and only by a factor of 2.8 when it is not. In a production setup where domestic and foreign linkages interplay, the strength of domestic linkages is relevant in determining the extent of increase in output that is captured by domestic sectors. In fact, the paper showed that huge income differences among rich and poor countries may be explained when intermediate goods and weak links are present.

Building upon the analytical model of Jones (2011), Bartelme and Gorodnichenko (2015) constructed a comprehensive dataset of input-output tables from 106 economies, with a broad spectrum of development level from 1950 to 2015, and empirically established a strong and positive relationship between an economy's strength of linkages and output per worker and total factor productivity. That is, their model estimated that a one standard deviation increase in an economy's strength of linkages leads to a 15\%-35\% increase in output per worker. In their paper, an economy's strength of linkages is measured by deriving an average output multiplier defined by the Leontief inverse matrix or the elasticity of gross output with respect to a change in aggregate productivity.

Among more recent contributions, Tang, Wang, and Wang (2020) conduct a firm-level analysis measuring the domestic segment of GVCs in the PRC. This is derived by getting the indirect domestic value added (DVA) as a share of total exports. This methodology, however, requires firmlevel composition data, which may not be available for many countries of interest. 
Another alternative measure of agglomeration is the Kearney reshoring index, which is derived by getting the year-on-year change in the manufacturing import ratio (Kearney 2021). ${ }^{1}$ The index captures the amount of inputs sourced domestically. However, the insight that can be obtained from the index remains limited to domestic linkages in the manufacturing sector. This paper modifies the Kearney reshoring index to include all multiregional input-output table (MRIOT) sectors in order to create a meaningful comparator for the agglomeration index.

Mercer-Blackman, Foronda, and Mariasingham (2017) formally developed an agglomeration index measuring the strength of forward and backward linkages of an economy. In their paper, the index is defined by taking the row and column sums of the Leontief inverse matrix of sectors with significant contribution in the production process. This paper proposes a refinement of this index. A base agglomeration index that measures the extent to which value added is sourced from and/or absorbed by domestic sectors is constructed. This improves on existing measures for two reasons. First, a value-added approach captures indirect effects of domestic linkages, which are not captured by measures based on import and output multipliers. Second, it creates a benchmark that determines whether a sector in the economy (henceforth, economy sector) has high or low agglomeration, relative to the world. This allows for an analysis of agglomeration in the global context at a sector level, using an indicator that is comparable across economies. Overall, the base measure attempts to capture the concentration of value added in the domestic sectors. In addition, the index is extended to account for the distribution of value added within the domestic sectors. The need to account for the distribution of value added rises from the fact that activities may be limited to certain domestic sectors. Economy sectors whose DVA are concentrated in specific sectors are unable to generate second-round effects to other domestic sectors, limiting its impact to the overall economy. This adjustment attempts to capture the concentration of domestic activities within the domestic sectors.

The next section provides a discussion on how the base agglomeration indexes are constructed based on the value-added decomposition approach by Wang et al. (2017). Section III discusses the agglomeration indexes adjusted for the distribution of value added within the domestic sectors and compare them with the base index. Section IV compares the base agglomeration index with existing measures of reshoring to assess its performance. Section $\vee$ concludes the paper.

\section{MEASURING AGGLOMERATION}

As previously discussed, the concept of agglomeration centers around location (Fujita and Thisse 1996). At a firm level, studies on agglomeration examine the extent to which firms cluster in certain areas, and which factors attract firms to locate operations in these areas. More importantly, the existing literature explores how concentration of economic activity in certain areas affects the domestic economy (Feldman 1999, Koenig 2009).

Similar concerns exist in the globalized economy. As economies continue to participate in global trade, the effect of these activities on the domestic economy appears at the forefront. On one hand, there is evidence that domestic sectors, which are not directly participating in global trade, nevertheless do so indirectly by providing intermediate inputs to the GVC sectors (Tang, Wang, and Wang 2020). This

1 The manufacturing import ratio is defined as imported inputs over domestic output of the manufacturing sector. 
implies that measures of participation to GVC activities underestimate the true extent of globalized activities, as they fail to capture the contribution of the domestic sectors (Mercer-Blackman, Foronda, and Mariasingham 2017). On the other hand, the recent trends of slowbalization, which are characterized by a stagnation in overall trade activities, highlight how economies are trying to reshore activities once located elsewhere (D'Urbino 2019, Titievskaia et al. 2020). This, in turn, raises concerns on export-led models of growth and the future of GVCs. Measures of domestic linkages provide insights on these factors by determining how the domestic sectors are situated in the context of a global economy.

The agglomeration index proposed in this paper seeks to provide a measure of the strength of domestic linkages by looking at how much value added is sourced from and/or absorbed in the domestic economy sectors given the production of final goods in the other sectors. This is an improvement to existing indexes, as it is not limited in capturing activities associated with reshoring. In addition, the use of value added accruing to the domestic sectors provides a better sense of how much goes to the domestic sectors, in contrast to indexes based on output multipliers. To construct the index, this study employs the value-added decomposition framework by Wang et al. (2017).

\section{A. Constructing the Index}

Assume that there are $G$ economies and $N$ sectors. Consistent with the input-output analysis framework, let the matrix $A_{G N \times G N}$ denote the global technical coefficient matrix and $B_{G N \times G N}$ the corresponding global Leontief inverse (Miller and Blair 2009). Define $A^{d}$ as the matrix containing the blocked diagonal elements of $A$ and $A^{f}=A-A^{d}$ as the matrix containing entries outside of the blocked diagonal. Thus, $A^{d}$ and $A^{f}$ contain the domestic and foreign elements of $A$, respectively. This generates the local Leontief inverse, $L_{G N \times G N}$, computed as $\left(I-A^{d}\right)^{-1}$. Lastly, define $V_{G N \times 1}$ as a vector containing the value added per unit of output in each economy sector and $Y_{G N \times 1}$ as the final demand vector for each economy sector.

As shown by Wang et al. (2017), the matrix $\widehat{V} B \widehat{Y}_{G N \times G N}$ shows the distribution of value added across different economy sectors. ${ }^{2}$ Column elements of $\widehat{V} B \hat{Y}$ describe the distribution of value added embodied in the final goods of the $j^{\text {th }}$ sector. Thus, the column sum of $\widehat{V} B \hat{Y}$ is equivalent to the total final goods production in an economy sector. Decomposing this obtains:

$$
\begin{aligned}
Y^{T}=V B \hat{Y} & =V L \hat{Y}^{d}+V L \hat{Y}^{f}+V L A^{f} L \hat{Y}^{d}+V L A^{f}\left(B \hat{Y}-L \hat{Y}^{d}\right) \\
& =Y_{D}+Y_{R T}+Y_{G V C_{S}}+Y_{G V C_{c}}
\end{aligned}
$$

Equation 1 describes where value added comes from: value added embodied in the final goods of sector $j$ comes from the domestic sectors $\left(Y_{D}\right)$, activities associated with traditional trade $\left(Y_{R T}\right)$, and GVC activities $\left(Y_{G V C_{S}}, Y_{G V C_{c}}\right)$. Meanwhile, row elements of $\widehat{V} B \hat{Y}$ show how value added generated in one economy sector is absorbed in the final-goods products of all economy sectors. As such, the row sum of $\widehat{V} B \hat{Y}$ allows the decomposition of gross value added into:

$$
\begin{aligned}
V a^{T}=\hat{V} B Y & =\hat{V} L Y^{d}+\widehat{V} L Y^{f}+\widehat{V} L A^{f} L Y^{d}+\hat{V} L A^{f}\left(B \hat{Y}-L Y^{d}\right) \\
& =V_{D}+V_{R T}+V_{G V C_{s}}+V_{G V C_{c}}
\end{aligned}
$$

2 Matrices denoted by a hat indicate a diagonal matrix whose diagonal elements are the elements of a vector. For example, an $N \times N$ matrix $\hat{x}$ is a diagonal matrix whose diagonal entries contain the elements of the vector $x_{N \times 1}$. 
Analogously, equation 2 describes where value added is absorbed, either in the domestic sectors $\left(V_{D}\right)$, activities associated with traditional trade $\left(V_{R T}\right)$, or GVC activities $\left(V_{G V C_{S}}, V_{G V C_{C}}\right)$. To determine the concentration of economic activities to the domestic sectors, it is important to look at how much value added comes from and/or is absorbed in the domestic sectors, given another sector's production of final goods and services. This is captured by the terms $Y_{D}$ and $V_{D} . Y_{D}$ captures final goods absorbed domestically whose value added is sourced domestically. Simply put, $Y_{D}$ captures local production for local consumption. Meanwhile, $V_{D}$ pertains to value added generated by each economy sector that is absorbed domestically as final goods. Both terms capture activities that do not involve cross-border trade.

These calculations provide the basis for the agglomeration indexes. Let $\Theta_{(j, r, t)}=Y_{(j, r, t)}^{D} / Y_{(j, r, t)}$ be the share of the domestic sectors to the total value of final goods production in economy $r$ sector $j$ at time $t$. The backward agglomeration index of sector $j$ in economy $r, A G G_{(j, r, t)}^{B}$, is defined as:

$$
A G G_{(j, r, t)}^{B}=\frac{\Theta_{(j, r, t)}}{\sum_{\tau=\mathrm{t}-1}^{t} \sum_{\mathrm{r}=1}^{G} \frac{\gamma_{(j, r, \tau)}}{2} \Theta_{(j, r, \tau)}}
$$

where $\gamma_{(j, r, \tau)} \in(0,1)$ is the share of economy $r$ to the total global output of sector $j$. The numerator is the share of final goods consumed domestically in $(j, r)$ whose value added comes from the domestic sectors in the total final demand for $(j, r)$. The denominator is the 2-year moving average of the same share for all $G$ economies.

Thus, the backward agglomeration index captures the share of $Y_{D}$ to $Y$ against the global average for that sector. A value of $A G G_{(j, r, t)}^{B}>1$ implies that the value added coming from the domestic sectors in the final goods production of sector $j$ in economy $r$ is higher than the world average. This indicates a case of high backward agglomeration. Consequently, a value less than 1 denotes a case of low backward agglomeration.

The construction of the forward agglomeration index is analogous. Let $\Phi_{(j, r, t)}=$ $V_{(j, r, t)}^{D} / V a_{(j, r, t)}$ be the share of value added generated in $(j, r)$ that is absorbed domestically as final goods. The forward agglomeration index of sector $j$ in economy $r, A G G_{(j, r, t)}^{F}$, is defined as:

$$
A G G_{(j, r, t)}^{F}=\frac{\Phi_{(j, r, t)}}{\sum_{\tau=\mathrm{t}-1}^{t} \sum_{\mathrm{r}=1}^{G} \frac{\gamma_{(j, r, \tau)}}{2} \Phi_{(j, r, \tau)}}
$$

The $A G G^{F}$ index compares the value added that is absorbed in domestic production relative to the world average. A value of $A G G_{(j, r, t)}^{F}>1$ implies that the final goods of sector $j$ in economy $r$ generates more value added to the domestic sectors relative to the global average for that sector. Consequently, a value less than 1 denotes a case of low forward agglomeration.

Equations 3 and 4 depict backward and forward agglomeration indexes at an economy sector level at time $t$. To generate agglomeration indexes at an economy level, the weighted average of the indexes is computed, using gross output for the $j^{\text {th }}$ sector $\left(\omega_{j}\right)$ as weights. Thus, for economy $r$, the backward and forward agglomeration indexes are:

$$
A G G_{(r, t)}^{B}=\sum_{j=1}^{N} \omega_{j} A G G_{(j, r, t)}^{B}
$$




$$
A G G_{(r, t)}^{F}=\sum_{j=1}^{N} \omega_{j} A G G_{(j, r, t)}^{F}
$$

By construction, we expect a correlation between backward and forward agglomeration. Recall from equations 1 and 2 that the indexes come from the matrix $\hat{V} L \hat{Y}^{d}$, which captures value added distributed domestically. Thus, economy sectors with higher forward agglomeration are backward agglomerated, for a given period. What distinguishes the two indexes are the direction that the value added takes. The backward agglomeration index captures where DVA comes from relative to the world average; whereas, the forward agglomeration index depicts where DVA goes.

The values of $A G G^{B}$ and $A G G^{F}$, together, can be used to classify an economy sector's state of agglomeration. Since a value of 1 does not deviate from the average, we can use it as the benchmark for classification. Low agglomeration economies pertain to those with low backward and forward agglomeration indexes $\left(A G G^{B}<1, A G G^{F}<1\right)$. Low backward agglomeration implies that final goods of economy sectors in this class are typically not sourced from the domestic sectors. Concurrently, low forward agglomeration implies that value added from these economy sectors that is absorbed in domestic production is limited. This, in turn, signals the sector's limited ability to generate domestic value added through forward linkages. An extreme example is an enclave sector, which is vertically integrated in global production and does not source inputs domestically (Mercer-Blackman, Foronda, and Mariasingham 2017).

Reshoring economies are characterized by high backward agglomeration and low forward agglomeration. Economy sectors belonging to this class source their inputs domestically, resulting in a high share of DVA embodied in the final goods production. The recent trend of those in the manufacturing sector relocating back to their respective domestic economies and sourcing intermediate inputs domestically is captured by this class.

Meanwhile, DVA-generating economies have high forward agglomeration but low backward agglomeration. Economy sectors in this class generate value added to the domestic sectors through forward linkages, that is by producing final goods that are later used to produce output in the domestic sectors.

Lastly, high agglomeration economies have high backward and forward agglomeration. Economy sectors in this class source their inputs domestically, capturing reshoring activities. In addition, however, they produce products that are used as intermediate inputs by the domestic sectors, implying value-added generation through forward linkages. Hence, domestic linkages in the backward and forward sense are strong for these types of economy sectors.

Figure 1 illustrates this using an agglomeration map. This highlights the advantage of the agglomeration index to related measures. Indexes such as the Kearney reshoring index capture the extent to which the manufacturing sector is increasingly sourcing intermediate inputs domestically. However, it does not capture the same action for other economy sectors, and it does not measure value added absorbed domestically through final goods used in domestic production. The agglomeration indexes developed in this paper allow not just for the analysis of reshoring, but for an analysis of value added generated in the domestic sectors via forward linkages. The map can be applied at economy sector level, using the indexes constructed in equations 3 and 4, and at an economy level, by aggregating the indexes using output as weights. In the subsequent sections, the agglomeration indexes are compared to a comparator index to assess their performance. Trends in agglomeration are examined to uncover the implications of agglomeration to GVCs. 
Figure 1: The Agglomeration Map

\begin{tabular}{|c|c|}
\hline $\begin{array}{c}\text { Reshoring Economies } \\
A G G^{F}<1, A G G^{B}>1\end{array}$ & High Agglomeration \\
\hline Low Agglomeration & $A G G^{F}>1, A G G^{B}>1$ \\
$A G G^{F}<1, A G G^{B}<1$ & DVA-Generating Economies \\
\hline
\end{tabular}

$A G G^{B}$ = backward agglomeration index, $A G G^{F}=$ forward agglomeration index, DVA = domestic value added.

Source: Authors' illustration.

\section{B. Data}

To construct the agglomeration indexes, the study employs the Asian Development Bank's (ADB) MRIOT. This extends the tables sourced from the World Input-Output Database (WIOD) by adding 19 economies from Asia and the Pacific region to the original 43 WIOD economies (Timmer et al. 2015). A residual "rest of the world" entity accounts for all other economies. Overall, the MRIOT includes 62 economies and the "rest of the world." Each economy in the MRIOT is comprised of 35 sectors. A description of the MRIOT and sectors included in the analysis is given in Appendix 1.

\section{Agglomeration and Global Value Chains}

The recent decades have changed the landscape of global trade. Several proponents argue that the period of hyperglobalization, characterized by unprecedented gains in global trade, is over. After 2008, evidence showing the slowdown of cross-border movement of goods and services, as well as investment, marked the era of slowbalization (D'Urbino 2019, Titievskaia et al. 2020).

Two strands of literature arise from this. One strand explores the possibility that global trade is taking a different shape and that current measures are unable to capture the overall extent of trade activities (Titievskaia et al. 2020). The other strand, as explored in the previous section, is consistent with some literature showing signs of reshoring, where manufacturing firms relocate back to their domestic economies. Under this strand, the contribution of manufacturing to domestic employment and the inability of developed economies to respond to external shocks have raised the incentive to relocate back to the domestic economy (Pegoraro, Propris, and Chidlow 2020).

Both strands highlight the need for a measure of the strength of domestic linkages. Recall that the domestic sectors contribute to GVC activities indirectly, either by providing intermediate inputs to sectors directly engaging in GVC activities, or by using products of the GVC sectors as intermediate inputs (Beverelli et al. 2015; Mercer-Blackman, Foronda, and Mariasingham 2017). Because very few firms engage directly in trade, either via exports or GVCs, current measures of GVC participation do not capture the contribution of the domestic sectors to global trade activities (Bernard et al. 2007). An index measuring the strength of domestic linkages fills in this gap. In terms of reshoring, an index measuring domestic linkages also captures the extent to which different economy sectors are sourcing intermediate inputs locally. Overall, the agglomeration indexes attempt to provide a measure of the 
strength of domestic linkages across economy sectors, thereby providing a better picture of the GVC activities across the globe.

\section{(1) Economy-Level Trends}

Figure 2 maps economy-level agglomeration indexes in the agglomeration map derived from equations 5 and 6. Economy-level agglomeration exhibits heterogeneity over time. From 2007 to 2012, about $30 \%$ of economies showed an increase in either backward or forward agglomeration. This would include high-income and upper middle-income economies such as Canada, Singapore, the PRC, and Malaysia, as well as some lower-middle-income economies such as the Philippines and Cambodia. In some cases, increases in either backward or forward agglomeration result in a change in an economy's agglomeration classification. For example, increases in backward agglomeration have pushed the PRC from a DVA-generating class to a high-agglomeration economy in the said period. In a similar vein, increases in both forward and backward agglomeration have changed the Philippines' agglomeration class from low agglomeration to high agglomeration. In other cases, increases in the indexes do not necessarily result in a change in agglomeration class, as exhibited by Malaysia.

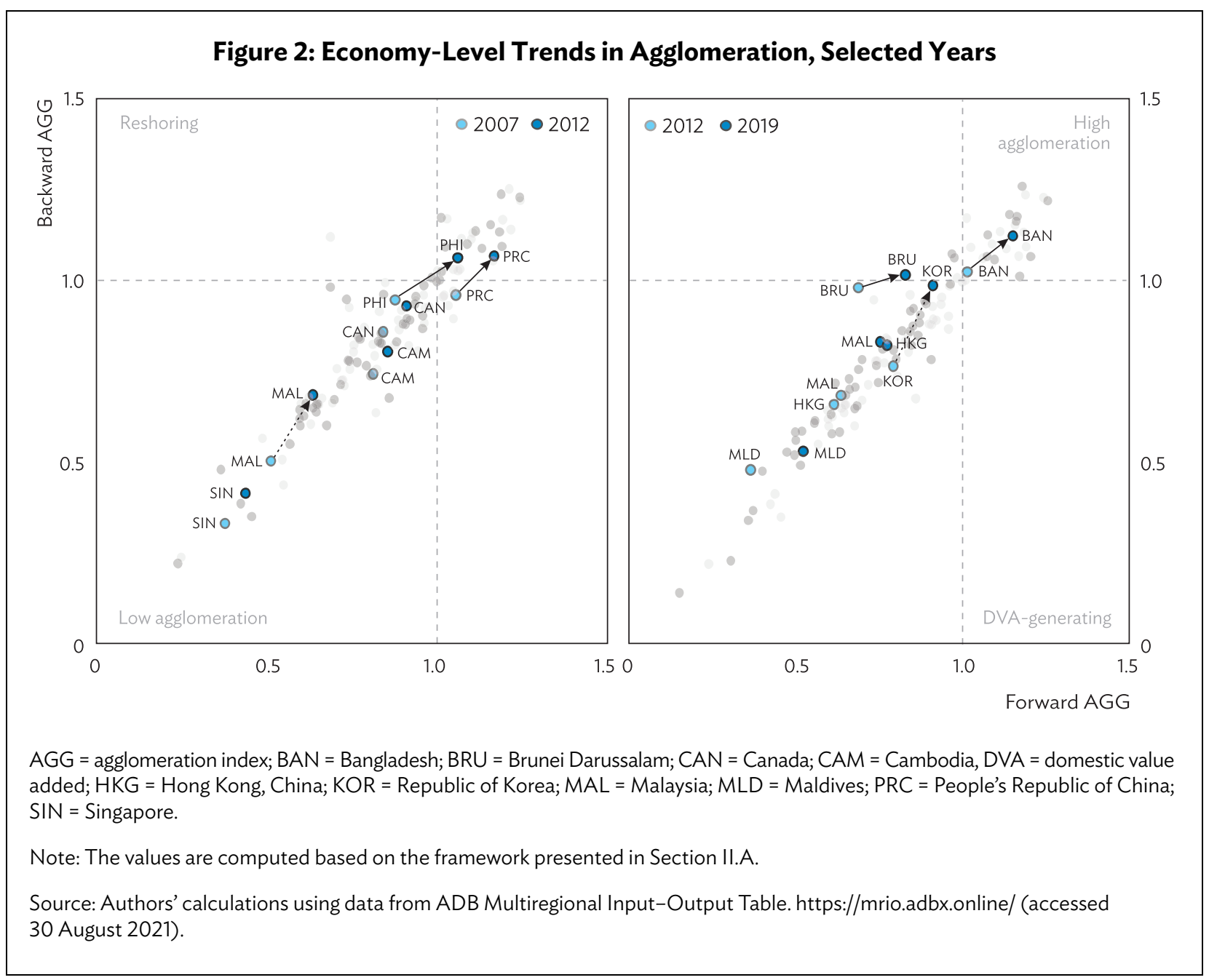


From 2012 to 2019, about 26\% of the economies exhibited an increase in either backward or forward agglomeration. Economies such as Maldives; Hong Kong, China; the Republic of Korea; Malaysia; Brunei Darussalam; Bangladesh; the Kyrgyz Republic; and Indonesia record increases in both indexes. In the case of Brunei Darussalam, this resulted in a shift from low agglomeration to reshoring class. The increase in both indexes retains the agglomeration class of the Republic of Korea but brings it near the border of agglomeration classes. Meanwhile, the increase in both indexes reinforce Bangladesh as a high-agglomeration economy over the years.

\section{(2) Sector Trends}

The manufacturing sector illustrates interconnectedness across economy sectors. Production of t-shirts, for example, involves activities occurring at different geographical areas. In the initial stage, cotton is grown in the US and later sold to the PRC. The PRC, in turn, uses these intermediate inputs to produce apparel, which may be resold to the US for imprinting logos, or to other economies as furniture padding (OECD 2013). Given the role of the manufacturing sector to GVCs overall, it is interesting to examine the linkages it forms with other domestic sectors. The agglomeration indexes allow for an analysis of the domestic concentration of value added at a sector level. Figure 3 focuses on the light manufacturing sector, comprised of food, beverages, and tobacco; textiles and textile products; leather, leather products, and footwear; wood and products of wood and cork; pulp, paper, printing, and publishing; rubber and plastics; other nonmetallic mineral; and manufacturing, not elsewhere classified (nec); and recycling.

\section{Figure 3: Agglomeration Trends for the Light Manufacturing Sectors, Selected Years}
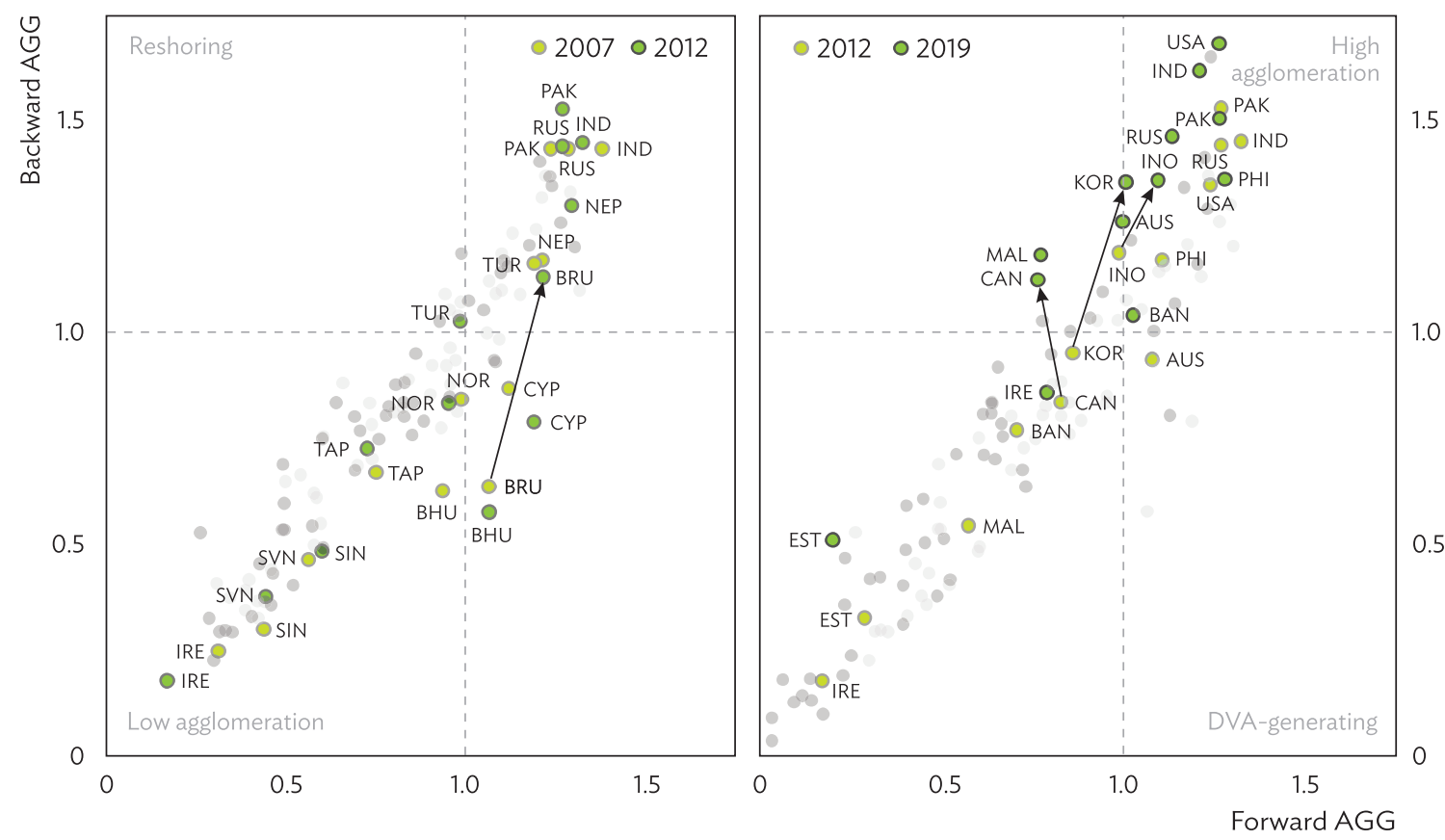

$\mathrm{AGG}=$ agglomeration index $\mathrm{AUS}=$ Australia; $\mathrm{BAN}=$ Bangladesh; $\mathrm{BHU}=$ Bhutan; $\mathrm{BRU}=$ Brunei Darussalam; $\mathrm{CAN}=\mathrm{Canada}$; CYP = Cyprus; DVA = domestic value added; EST = Estonia; IND = India; INO = Indonesia; IRE = Ireland; $K O R$ = Republic of Korea; MAL = Malaysia; NEP = Nepal; NOR = Norway; PAK = Pakistan; PHI = Philippines; RUS = Russian Federation; SIN = Singapore; SVN = Slovenia; TAP = Taipei,China; TUR = Turkey; USA = United States.

Note: The values are computed based on the framework presented in Section II.A. 
The Russian Federation, India, and Pakistan record the highest backward agglomeration for 2007 and 2012. Meanwhile, forward agglomeration is highest for India in both periods. The light manufacturing sector for these set of economies belongs to the high-agglomeration class. This implies that industries under the light manufacturing sector tend to source their inputs domestically, resulting in a high share of DVA embodied in their production of final goods. Moreover, the value added generated by the light manufacturing sector in these economies that are absorbed domestically through final goods are higher than the world average, suggesting the ability of these economies to generate value added domestically through forward linkages.

Apart from looking at levels of agglomeration indexes, increases or decreases in backward and forward agglomeration indexes may result in a shift in agglomeration class for some economies. In 2007 to 2012, 37\% of the economies exhibited an increase in either backward or forward agglomeration of their respective light manufacturing sector. Brunei Darussalam illustrates how a significant increase in backward agglomeration shifts its light manufacturing sector from a DVAgenerating class to a high-agglomeration economy sector.

Between 2012 to 2019, about 27\% of economies have recorded an increase in at least one of their agglomeration indexes. The Republic of Korea and Indonesia show increases in both indexes, causing a change in their agglomeration class. The Republic of Korea's light manufacturing sector moves from low agglomeration to high agglomeration, while Indonesia's light manufacturing sector shifts from being a reshoring class to a high-agglomeration economy. Canada presents a case of an increase in backward agglomeration and a decline in forward agglomeration. Intuitively, this means Canada's light manufacturing sector exhibits a significant increase in local production for local consumption within the specified period. This shifts Canada's light manufacturing sector from a lowagglomeration class to a reshoring class. Overall, changes in agglomeration within the light manufacturing sector can be attributed to supply chain changes and are unable to capture changes in product types. Increased backward agglomeration suggests that these sectors source intermediate inputs domestically, while increases in forward agglomeration capture the extent to which domestic sectors under the light manufacturing sector consume final goods. However, it is possible to extend the agglomeration indexes to capture changes in product types through the use of national input-output tables disaggregated at a product level. This will be explored in the future as more data becomes available.

\section{(3) Agglomeration and Other Global Value Chain Indicators}

The narrative of slowbalization suggest that economies are shifting activities located elsewhere back to the domestic economy. This, in turn, signals an influx of activities to the domestic economy and less reliance on global production processes. To this end, the agglomeration indexes provide an interesting insight, as they map the concentration of value added to the domestic economy. This raises the need to examine the relationship between agglomeration of economy sectors and the incentive to participate in GVCs. Borin and Mancini (2019) propose an alternative framework in extracting the GVC-component of an economy sector's exports, which improves on existing indicators measuring GVC participation. ${ }^{3}$ Utilizing this measure, Figure 4 presents the economy sector level scatterplot of GVC participation and the agglomeration indexes defined in equations 3 and 4 for 2019.

3 Borin and Mancini (2019) present a trade-based measure of GVC participation, which calculates with GVC component of an economy sector's gross exports. The participation index employed in this paper sums up the trade-based backward and forward GVC participation rates. 
A negative correlation persists between backward and forward agglomeration, and GVC participation. Back of the envelope regressions reveal that a $1 \%$ increase in backward agglomeration may result in a 0.004 to $0.090 \%$ decline in trade-based GVC participation. The analogous value for forward agglomeration is from 0.009 to $0.08 \%{ }^{4}$ Using a locally weighted scatterplot smoothing (LOWESS) estimator, however, a more nuanced relationship can be observed between GVC participation and agglomeration. For economy sectors with high backward $\left(A G G^{B}>1\right)$ or forward $\left(A G G^{F}>1\right)$ agglomeration, a positive correlation exists with trade-based GVC participation. This may indicate that economy sectors with high backward or forward agglomeration are able to channel gains from GVC participation due to its strong domestic linkages, which in turn create incentives for GVC participation. Overall, this suggests that the relationship between agglomeration and GVCs is more complex than what is initially imagined.

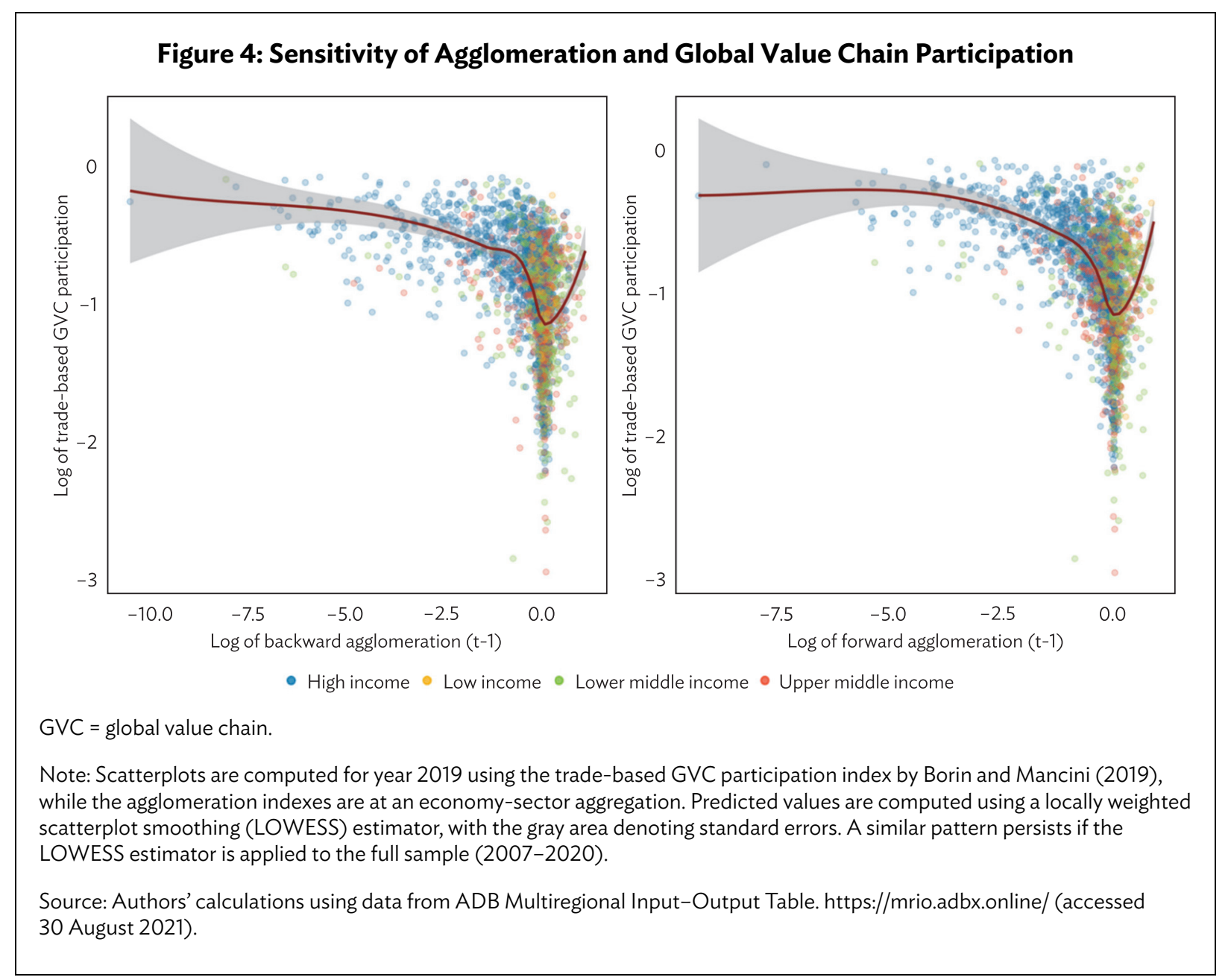

4 These results are based on regression of the log of trade-based GVC participation to agglomeration indexes. Results are available in Appendix 2. 


\section{CAPTURING CONCENTRATION OF ACTIVITIES WITHIN THE DOMESTIC SECTORS}

The agglomeration indexes perform well in capturing the concentration of value added to the domestic sectors. It is possible, however, to have a situation wherein value added sourced from and/or absorbed by the domestic sectors are concentrated in a few domestic sectors. At the extreme is a hypothetical economy where the DVA goes to a single sector, with very little indirect effects to other domestic sectors. In this case, even if the value added sourced from and/or absorbed by the domestic sectors is large, the breadth of this economy's domestic linkages is highly contentious.

Measures of domestic linkages can be extended, therefore, to include not only how much economic activities can be attributed to the domestic sectors relative to the external sectors, but also the extent to which these activities are distributed within the domestic sectors. This section extends the agglomeration indexes proposed in Section II.A to account for the distribution of activities within the domestic sectors.

\section{A. Constructing the Adjusted Agglomeration Index}

To refine the agglomeration index, recall that the domestic components of the $\hat{V} B \hat{Y}$ matrix are captured in the matrix $\widehat{V} L \hat{Y}^{d}$, where equations 3 and 4 are derived. Denote $\bar{v}_{(y, r, t)}=\frac{1}{N} \sum_{i=1}^{N} v l y_{(i, r, t)}^{d}$ as the sample mean of the $j^{\text {th }}$ column of the $\hat{V} L \hat{Y}^{d}$ matrix. Intuitively, this indicates the average value added sourced from the domestic sectors for economy $r$ sector $j$. Let $\sigma_{v}^{2}(j, r, t)=\frac{1}{N-1} \sum_{i=1}^{N}\left(v l y_{(i, r, t)}^{d}-\right.$ $\left.\bar{v}_{(j, r, t)}\right)^{2}$ be the sample variance of the $j^{\text {th }}$ column of the $\hat{V} L \hat{Y}^{d}$ matrix, and $\sigma_{v}(j, r, t)$ be the sample standard deviation. The normalized standard deviation for $(j, r)$ is:

$$
s_{(j, r, t)}=\frac{\sigma_{v}(j, r, t)}{\overline{v l y}_{(j, r, t)}}
$$

Using this, the backward agglomeration index can be adjusted as follows:

$$
A G G_{(j, r, t)}^{B}=\frac{\Theta_{(j, r, t)} / s_{(j, r, t)}}{\sum_{\tau=\mathrm{t}-1}^{t} \sum_{\mathrm{r}=1}^{G} \gamma_{(j, r, \tau)} \Theta_{(j, r, \tau)} / 2 s_{(j, r, \tau)}}
$$

The normalized standard deviation captures the distribution of value added within the $j^{\text {th }}$ column of the $\hat{V} L \hat{Y}^{d}$ matrix. When value added is concentrated in a few sectors for economy $r$, $\sigma_{v}(j, r, t)$ and, consequently, $s_{(j, r, t)}$ become large. This, in turn, adjusts the numerator of equation 6 downwards. When the numerator of equation 8 declines faster than its denominator, the adjusted backward agglomeration index will be lower than the base. Thus, the normalized standard deviation discounts value added sourced from the domestic sectors by considering how that value added is distributed across other domestic sectors. Analogously, a smaller $s_{(j, r, t)}$ would imply a stronger interconnectedness within the domestic sectors, resulting in an upward adjustment of the backward agglomeration indexes. Note that in the special case of uniform distribution, $s_{(j, r, t)}$ is set to 1 so that the adjusted agglomeration index coincides with the base specification proposed in Section II. 
The adjustment for the forward agglomeration index can be constructed by applying the same process to the rows of the $\hat{V} L \hat{Y}^{d}$ matrix. Denoting $\bar{v}_{\bar{v}}(j, r, t)$ and $s_{(j, r, t)}$ as the sample mean and normalized standard deviation of the $j^{\text {th }}$ row of the $\hat{V} L \hat{Y}^{d}$ matrix, respectively, the forward agglomeration index becomes:

$$
A G G_{(j, r, t)}^{F}=\frac{\Phi_{(j, r, t)} / s_{(j, r, t)}}{\sum_{\tau=\mathrm{t}-1}^{t} \sum_{\mathrm{r}=1}^{G} \gamma_{(j, r, \tau)} \Phi_{(j, r, \tau)} / 2 s_{(j, r, \tau)}}
$$

\section{B. Base versus Adjusted Agglomeration}

The adjusted agglomeration indexes are estimated using the ADB MRIOT. Figure 5 depicts the changes in agglomeration classes after taking the distribution of activities within the domestic sectors into account. The term "base" refers to the base agglomeration index derived from equations 3 and 4, while the term "SD" refers to the adjusted agglomeration indexes derived from equations 8 and 9.

Figure 5: Changes in Agglomeration Class, 2007 and 2019

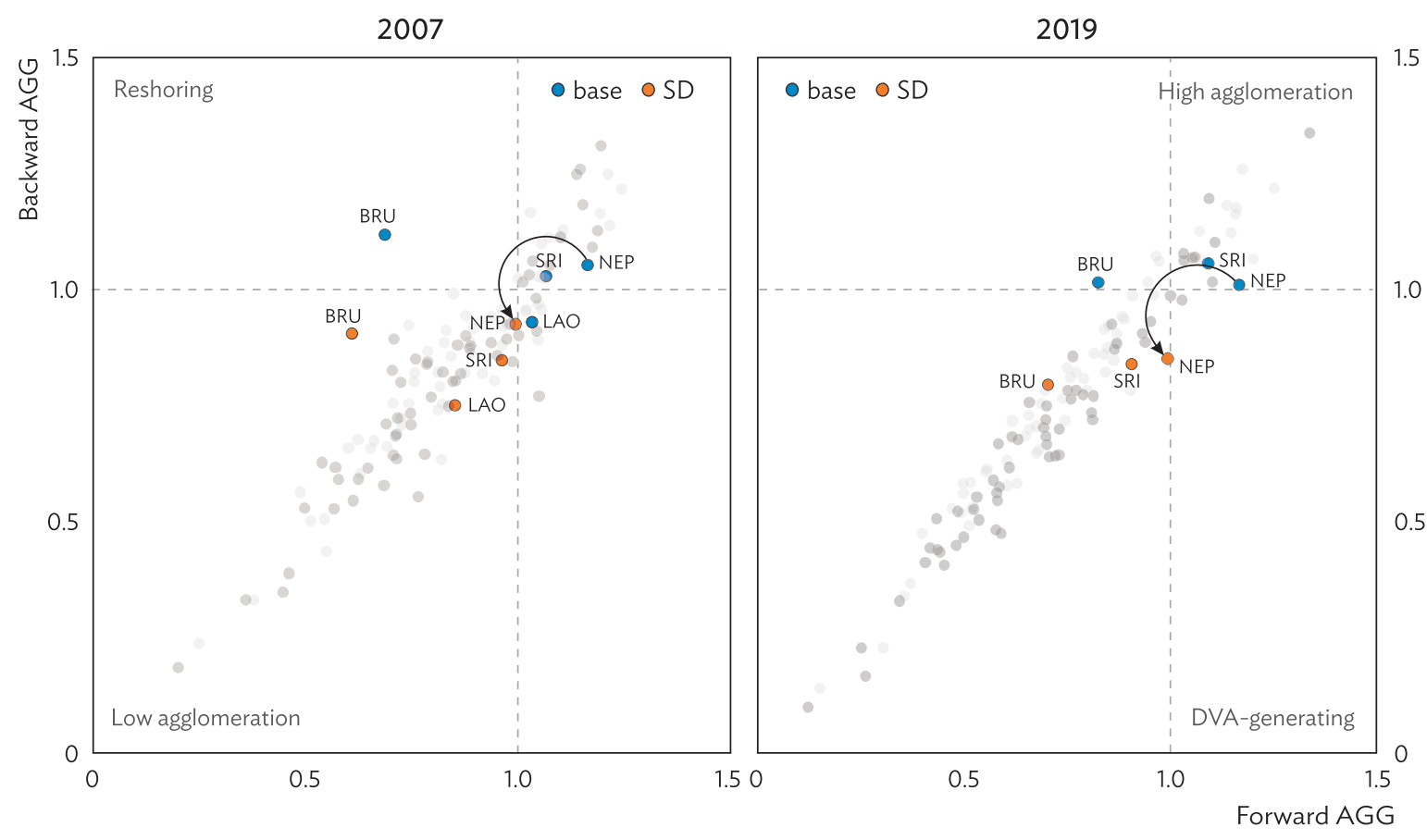

AGG = agglomeration index, BRU = Brunei Darussalam, LAO = Lao People's Democratic Republic, NEP = Nepal, SRI = Sri Lanka.

Notes:

1. The values are computed based on the framework presented in Section II.A, using the ADB MRIOT.

2. Colored elements indicate economies, which recorded changes in agglomeration class for years 2007 and 2019 , when the standard deviation approach for agglomeration is employed.

3. The term "base" refers to the base agglomeration index, while the term "SD" refers to the adjusted agglomeration indexes.

Source: Authors' calculations using data from ADB Multiregional Input-Output Table. https://mrio.adbx.online/ (accessed 24 September 2021). 
With the adjusted specification, five economies recorded a change in agglomeration class for 2007. These include lower-middle-income economies such as Bangladesh, Lao People's Democratic Republic, Sri Lanka, and Nepal. Similarly, Fiji, an upper-middle-income economy, also recorded shifts in agglomeration class. In 2019, three economies recorded changes in agglomeration class using the adjusted specification: Brunei Darussalam, Nepal, and Sri Lanka. For these sets of economies, high concentration of value added in selected domestic sectors adjusted the agglomeration indexes downwards, leading to a change in agglomeration class. Overall, this indicates that incorporating distribution of activities within the domestic sector matters in depicting the state of an economy's agglomeration.

The sector-level agglomeration indexes can be used to examine what drives the changes in agglomeration class at an economy level. Using the estimates for Nepal in 2019, Figure 6 depicts the sector-level backward and forward agglomeration indexes for the two specifications. Using the base specification, 18 sectors have exhibited high backward agglomeration $\left(A G G^{B}>1\right)$, while 29 sectors show high forward agglomeration $\left(A G G^{F}>1\right)$. After adjusting for the concentration of activities within the domestic sectors, however, the numbers declined to 10 sectors for backward agglomeration and 18 sectors for forward agglomeration. Value added absorbed domestically in sectors such as food and beverages (c3), leather (c5), paper (c7), rubber and plastics (c10), wholesale trade (c20), air transport (c25), transport activities, nec (c26), telecommunications (c27), and financial intermediation (c28) show high concentration. This results in a shift from high to low forward agglomeration for these sectors.

The agriculture sector (c1), where most of Nepal's output is concentrated, records a huge decline in forward agglomeration, resulting in a shift to low forward agglomeration. Overall, the decline in forward agglomeration for many sectors in Nepal drove the shift in its economy-level agglomeration towards the reshoring class.

Backward agglomeration has also declined in several sectors using the adjusted specifications. However, some sectors noted an increase in backward agglomeration using the adjusted specification. Postal and telecommunications (c27) and hotels and restaurants (c22), which contribute $4 \%$ and $3 \%$ of Nepal's gross output in 2019, respectively, show a higher backward agglomeration using the new specification. For these sectors, value added sourced domestically come from more sectors, implying stronger backward linkages within the domestic economy. In both cases, the new specification shifts the sector-level agglomeration into high backward agglomeration. 
Figure 6: Sector-Level Changes in Agglomeration of Nepal, 2019

a) Backward agglomeration

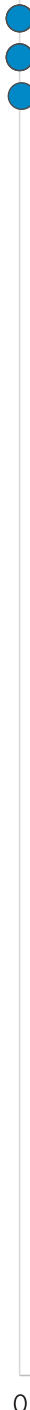

Water transport

Private households

Transport equipment $\bigcirc$ Textiles

Personal services, NEC

Inland transport

Construction

Transport activities, NEC

U Utilities

Business activities, NEC

Telecommunications

0 Paper

Health and social work

Hotels and restaurants

Real estate

Public administration

Metals

Education

Cinance

Retail trade

... Sale of motorcycles

Minerals, NEC

Air transport

Agriculture

Chemicals

00 Food and beverages

Mining

Wholesale trade

Refined fuels

$\infty$ Wood

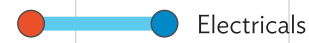

$\bigcirc$ Machinery, NEC

$\bigcirc$ Leather

Manufacturing, NEC

Rubber and plastics

0

1

2

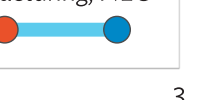

b) Forward agglomeration

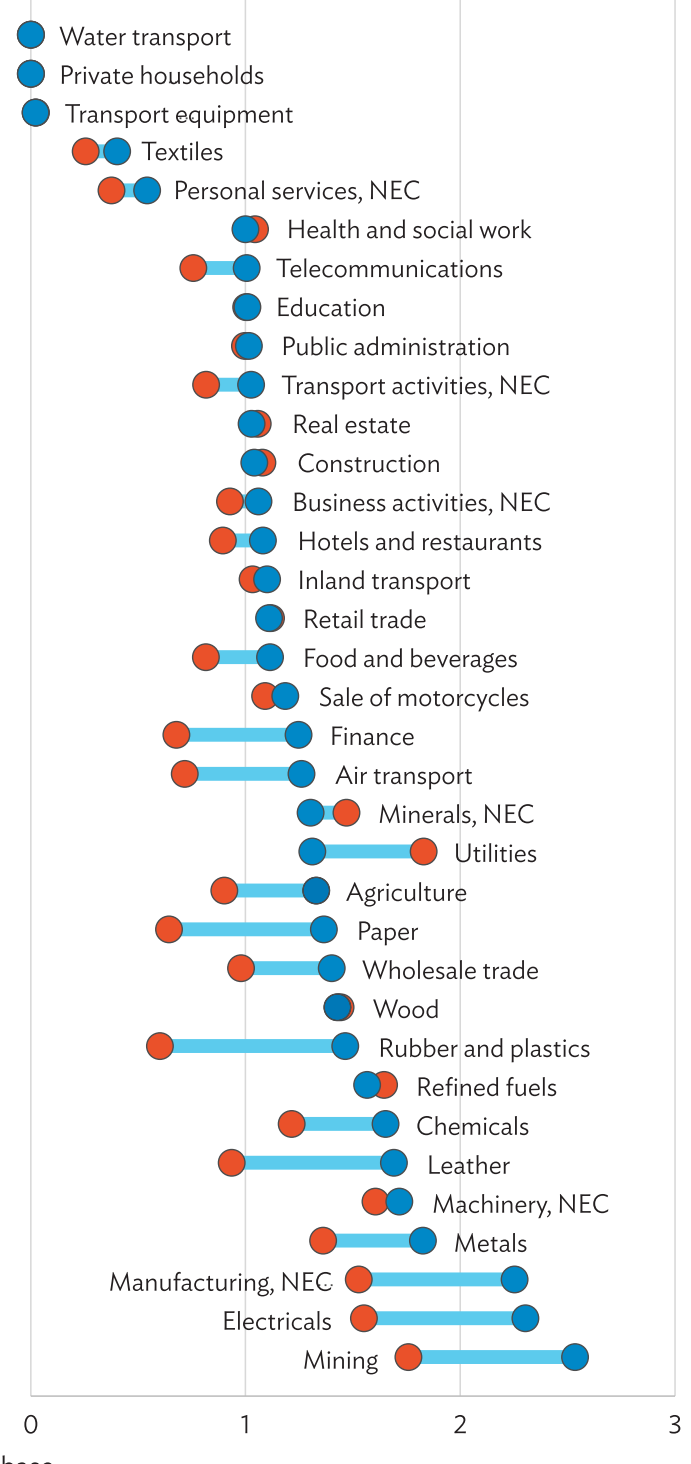

- SD obase

base = base agglomeration index, $\mathrm{SD}=$ adjusted agglomeration index, NEC = not elsewhere classified.

Note: The values are computed based on the framework presented in Section II.A.

Source: Authors' calculations using data from ADB Multiregional Input-Output Table. https://mrio.adbx.online/ (accessed 24 September 2021). 


\section{COMPARING AGGLOMERATION WITH EXISTING INDEXES}

To gauge how the agglomeration indexes capture the shift of activities once located elsewhere back to the domestic economy, it is best to compare these indexes with existing measures of reshoring. The Kearney reshoring index is a useful comparator, as it measures offshoring activities by looking at the year-on-year change of the import-to-domestic output ratio of the manufacturing sector (Kearney 2021). A negative reshoring index suggests offshoring, and a positive reshoring index provides the net reshoring activities of the manufacturing sector. This paper adopts the spirit of the Kearney reshoring index and modifies it to allow comparison with agglomeration indexes. The modified Kearney reshoring index (MKRI) gives the trade-off between imported and domestic inputs required to produce the additional output needed to satisfy a $\$ 1$ increase in final demand for the domestic sector. ${ }^{5}$ Here, a high reshoring index implies high agglomeration.

The agglomeration indexes perform well if they exhibit a significant correlation with the MKRI. With the value of 1 as the benchmark, an MKRI greater than 1 indicates offshoring, while an MKRI less than 1 indicates reshoring. For simplicity, the values are multiplied by -1 to show positive correlation with the agglomeration index.

\section{A. Correlations}

Economies with high backward agglomeration exhibit high reshoring index, and this is illustrated by the positive slope between the backward agglomeration index and the backward MKRI (Figure 7). Time periods 2012 and 2019 are used as references.

Some economies show different results using both indexes. This is the case for Cambodia, the Kyrgyz Republic, Nepal, Sri Lanka, among others, wherein the backward MKRI exhibits drastic changes for the enumerated economies despite having a steady backward agglomeration index. This could be attributed to differences in the way the two indexes are constructed. The value added approach used in constructing the agglomeration indexes allow for a more accurate measure of preferences between domestic and foreign sources of intermediate inputs, as it captures activities solely attributed to the domestic sectors. Despite this, the positive correlation between the two indexes suggest that the backward agglomeration index is consistent with existing measures of reshoring.

The backward agglomeration index and backward MKRI have a significant positive correlation at $0.71(p<0.0001)$ and $0.45(p<0.001)$ in 2012 and 2019, respectively. For both years, the economies found in the lower left are mostly high-income economies (e.g., Ireland and Luxembourg) suggesting that these economies rely on imported inputs for their production. This reliance on imported inputs has resulted in a low backward agglomeration index. Despite a low and steady backward agglomeration, two lower-middle-income economies (i.e., Cambodia and the Kyrgyz Republic) observe a high reshoring index in 2012, which changes to a low reshoring index in 2019. As in the previous case, these differences may be attributed to the way the indexes are constructed. Since the MKRI only considers imports ratio in gauging reshoring, the agglomeration index captures the inputs sourced domestically better than the MKRI.

5 The framework for constructing the modified Kearney reshoring index is found in Appendix 3. 
Figure 7: Scatterplots of Backward Agglomeration and Reshoring Indexes, 2012 and 2019

2012

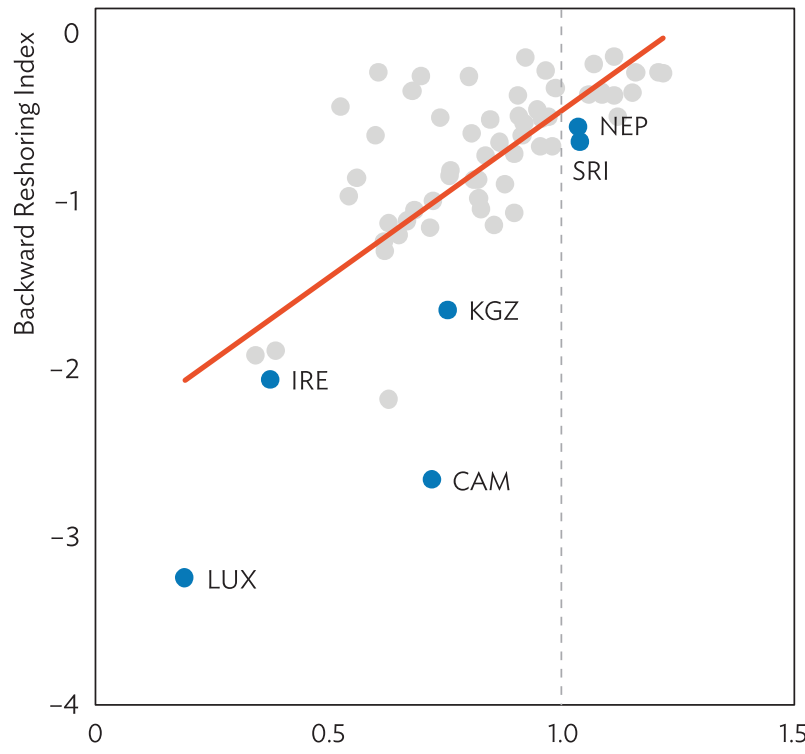

Correlation coefficient is $0.74(p<0.0001)$.
2019

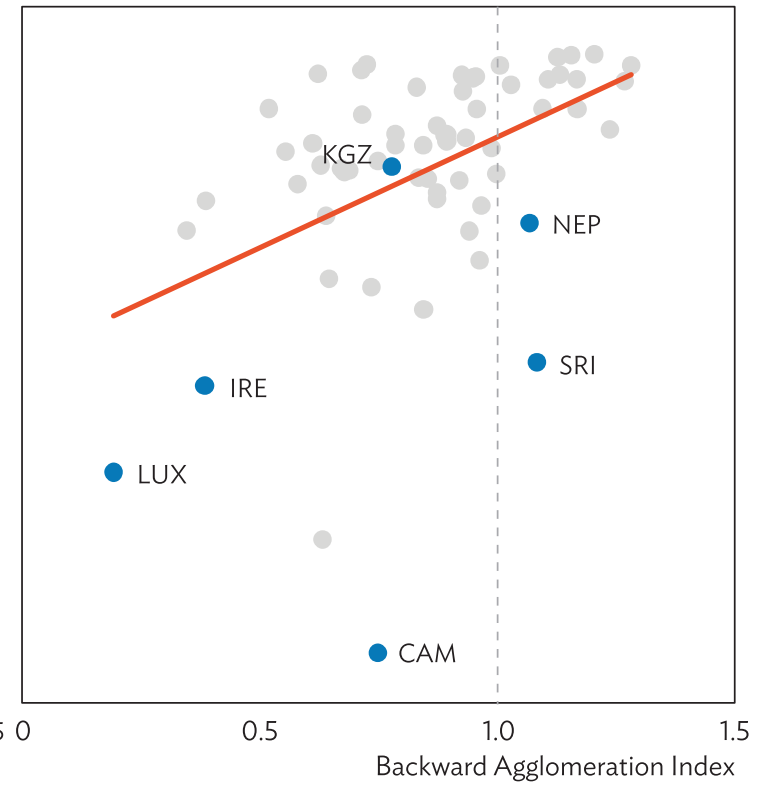

Correlation coefficient is $0.45(p<0.0001)$.

CAM = Cambodia, $I R E=$ Ireland, $K G Z=$ Kyrgyz Republic, $L U X=$ Luxembourg, NEP = Nepal, SRI = Sri Lanka.

Note: These are computed using the frameworks proposed in Section II.A and Appendix 3.

Source: Authors' calculations using data from ADB Multiregional Input-Output Table. https://mrio.adbx.online/ (accessed 5 October 2021).

Figure 8 illustrates the correlation between the forward agglomeration index and the forward MKRI. Economies with high forward agglomeration are expected to exhibit high reshoring index, illustrated by the positively sloped scatterplots in Figure 8. Periods 2012 and 2019 are similarly used as references.

As in the case with the backward indexes, some economies exhibit drastic changes in their forward MKRI despite a steady forward agglomeration index. Again, this can be attributed to methodological differences between the two approaches. However, the positive correlation between the two shows that the forward agglomeration index proposed in this paper reasonably captures the reshoring behaviors of the economies. The correlation coefficients are $0.61(p<0.001)$ and 0.32 $(p<0.001)$ in 2012 and 2019, respectively. In both years, the economies at the lower left are mostly high-income economies (e.g., Ireland and Luxembourg). However, some economies (e.g., Cambodia, the Kyrgyz Republic, and Slovenia) observe drastic changes in their forward MKRI within the 7-year period despite a steady forward agglomeration index. This, again, may be due to the differences in the way both indexes are constructed. 
Figure 8: Scatterplots of Forward Agglomeration and Reshoring Indexes, 2012 and 2019

2012

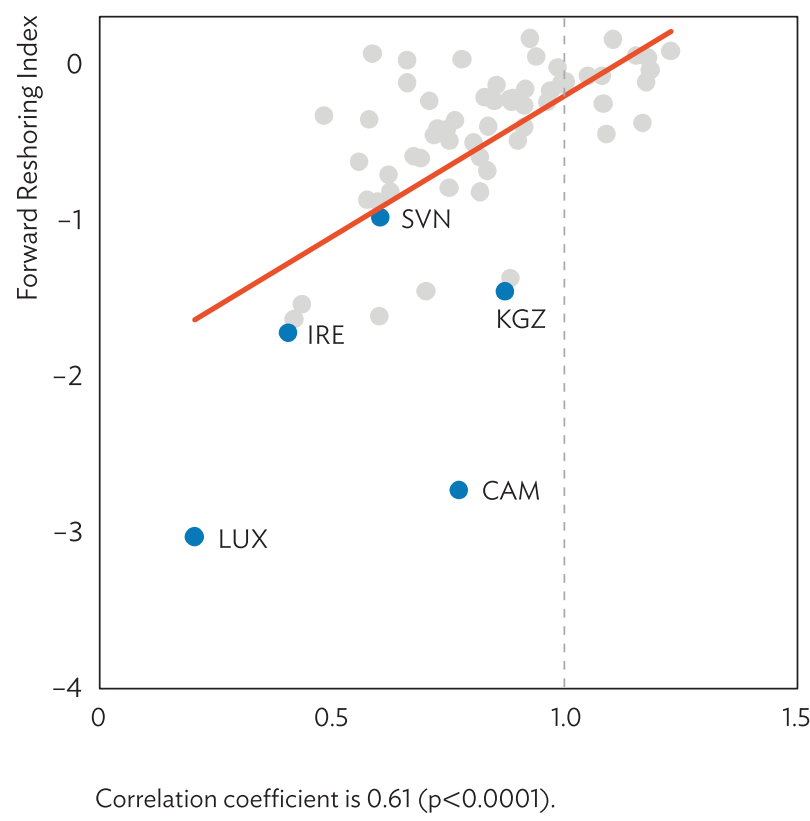

2019

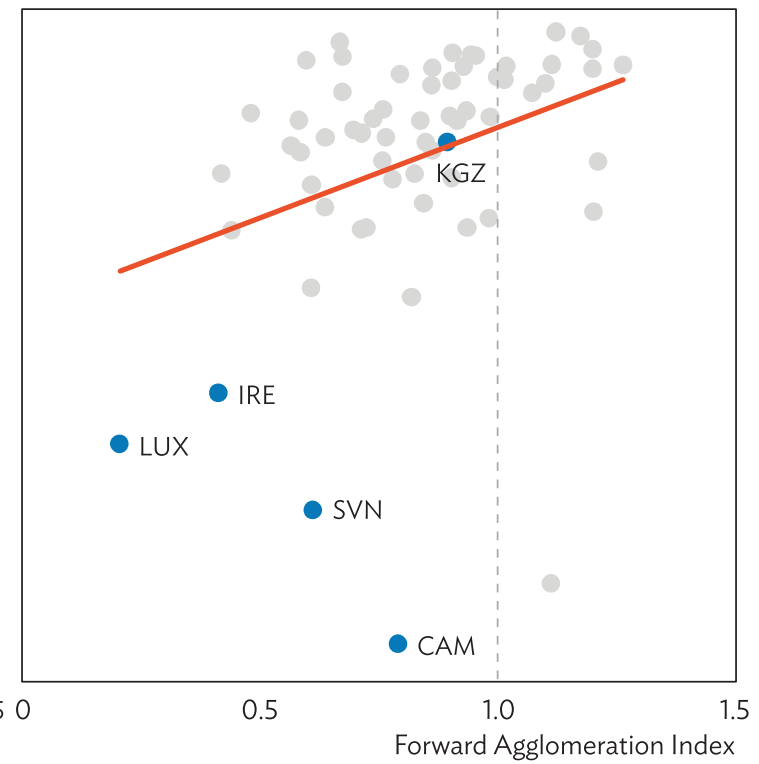

Correlation coefficient is $0.32(p<0.0001)$

CAM = Cambodia, $I R E=$ Ireland, $K G Z=$ Kyrgyz Republic, $L U X=$ Luxembourg, SVN = Slovenia.

Note: These are computed using the frameworks proposed in Section II.A and Appendix 3.

Source: Authors' calculations using data from ADB Multiregional Input-Output Table. https://mrio.adbx.online/ (accessed 5 October 2021).

For both agglomeration indexes, correlation with the MKRI weakens over time. This illustrates how the agglomeration indexes differ with existing indexes. As previously discussed, the proposed indexes isolate value added that can be attributed to the domestic sectors, which are not accounted for in the indexes like Kearney where issues of double counting domestic contribution may exist. Expansion of the GVC activities in 2019 will likely exacerbate these issues, resulting in a weaker correlation between the indexes. Hence, agglomeration indexes offer a more accurate way of measuring domestic linkages and result in a weak but significant correlation with existing indexes over time.

Overall, this section shows that the agglomeration indexes generate results consistent with an existing index and perform well in measuring the reshoring activities of an economy. Moreover, the agglomeration indexes provide a better measurement of concentration of activities in the domestic sectors as it is not limited to the import ratios in measuring reshoring.

\section{B. Year Trends}

To examine year-on-year movements using the four indexes, the analysis considers the top five economies for each index over the years. Figure 9 illustrates the differences between the indexes. The agglomeration indexes show a smooth trend, while the MKRIs are volatile. 


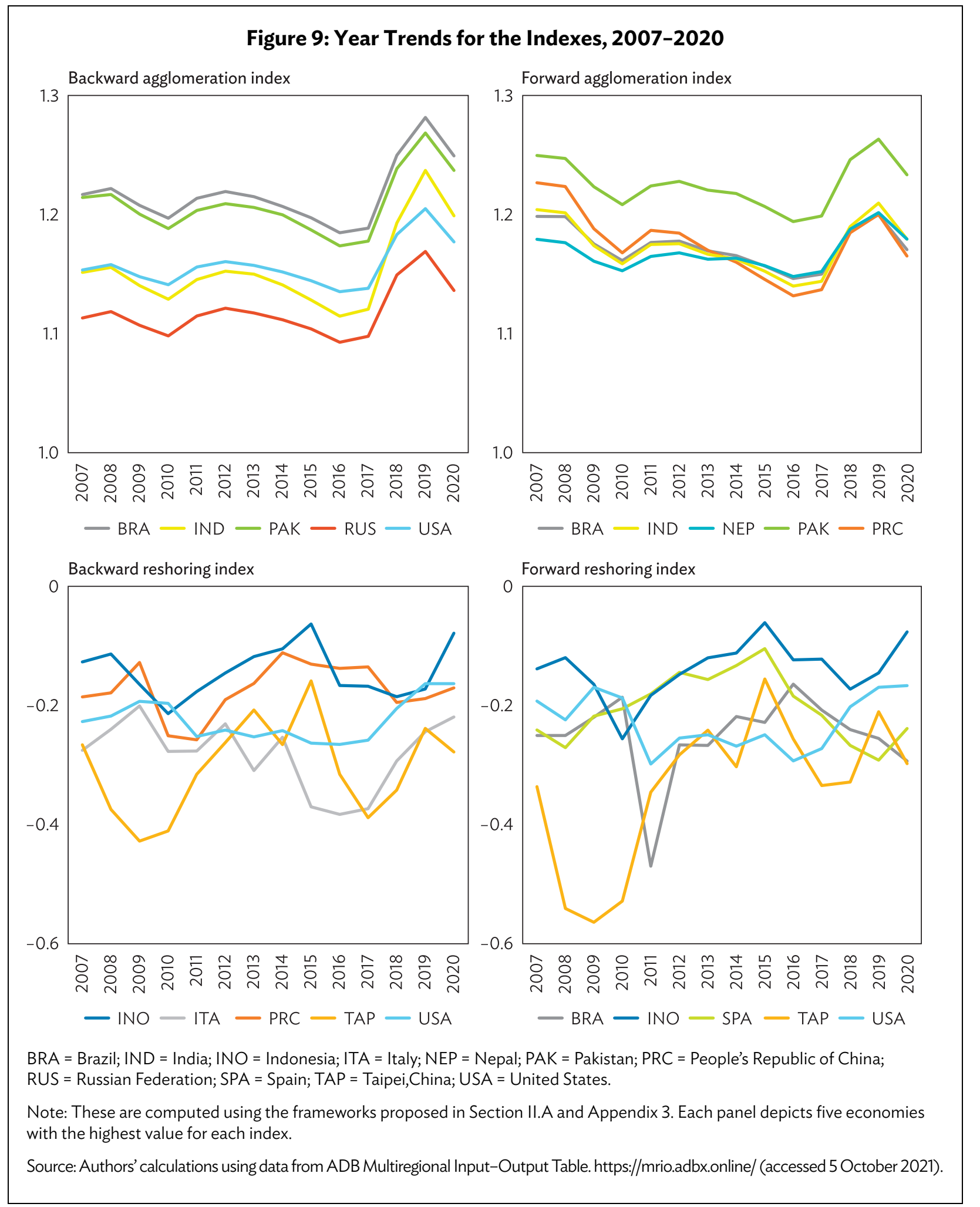

The five economies with the highest backward agglomeration index differ from the five economies with the highest backward MKRI, with the US as an exception. Here, the backward agglomeration index of the US (in blue) follows the same pattern as the backward MKRI. In 2018 and 2019, the increase in backward MKRI is coupled with an increase in backward agglomeration index. Moreover, in 2020, the decline in backward agglomeration mirrors that of the backward MKRI. 
Analogous to the backward indexes, the five economies having the highest forward agglomeration index are different from those with the highest forward MKRI, except for Brazil. While the forward MKRI of Brazil (in dark blue) shows a decline in 2011, the forward agglomeration index records a steady index of 1.17 from 1.16. This suggests that the agglomeration indexes offer a more accurate approach in capturing preferences of domestic over foreign inputs due to its value-added nature. This further implies that the agglomeration indexes present an improvement over existing measures of reshoring.

The subsequent figures provide further insights. Limiting the analysis to five economies with the highest backward agglomeration index, Figure 10 illustrates the unsteady trend of the backward MKRI of these economies, which is absent in the trend for backward agglomeration. A similar unsteady trend for the forward MKRI can be observed in Figure 11 for five economies with the highest forward agglomeration index.

Overall, the agglomeration indexes produce results consistent with existing reshoring indexes. Moreover, the value-added approach employed in constructing the agglomeration indexes offers a more accurate measure of the domestic concentration of economic activities. This improves on existing measures, which rely solely on imports in determining where an economy sector sources its inputs.

Figure 10: Top Five Economies Using the Backward Agglomeration Index, 2007-2020

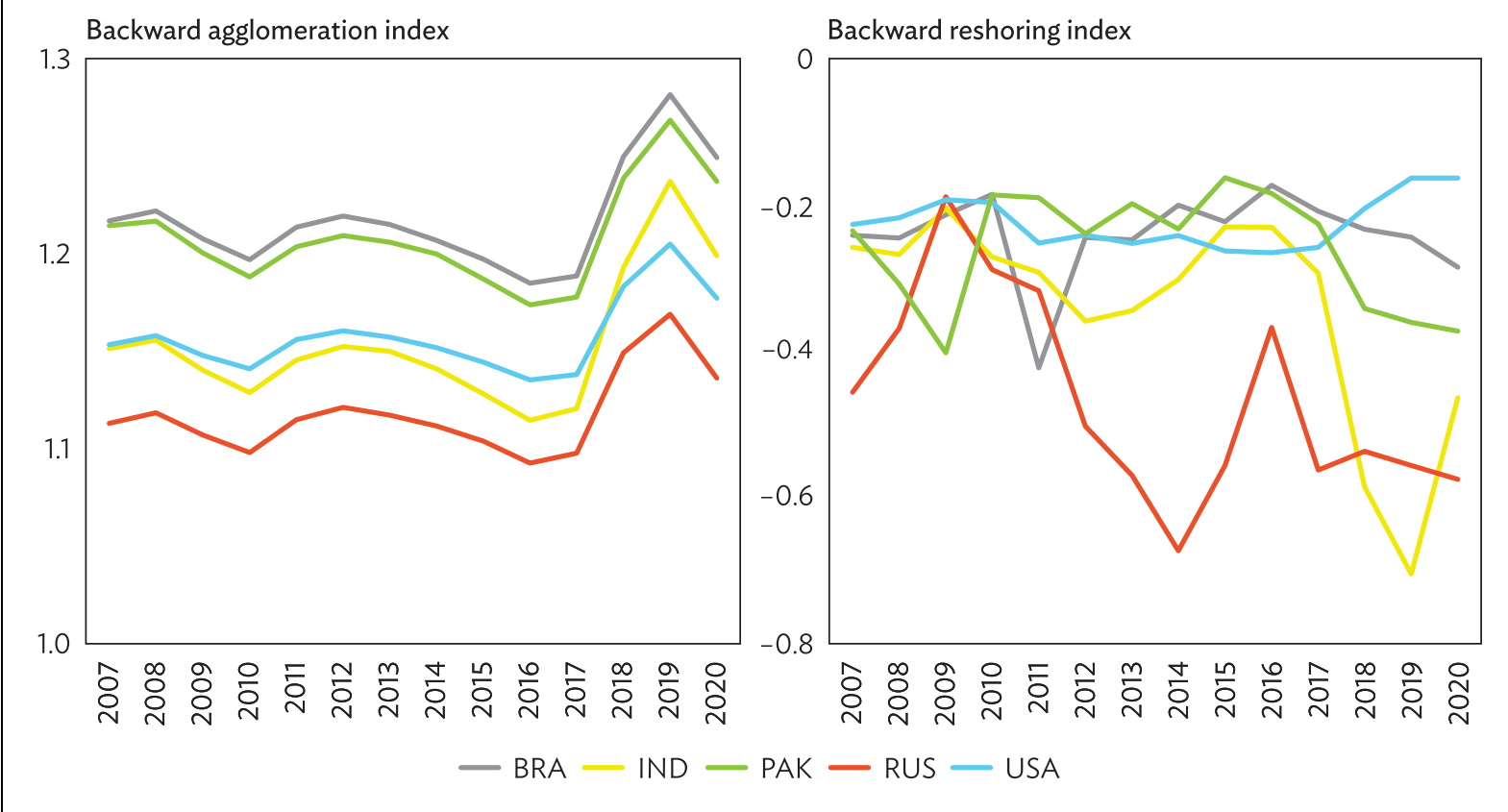

BRA = Brazil, IND = India, PAK = Pakistan, RUS = Russian Federation, USA = United States.

Note: These are computed using the frameworks proposed in Section II.A and Appendix 3.

Source: Authors' calculations using data from ADB Multiregional Input-Output Table. https://mrio.adbx.online/ (accessed 5 October 2021). 


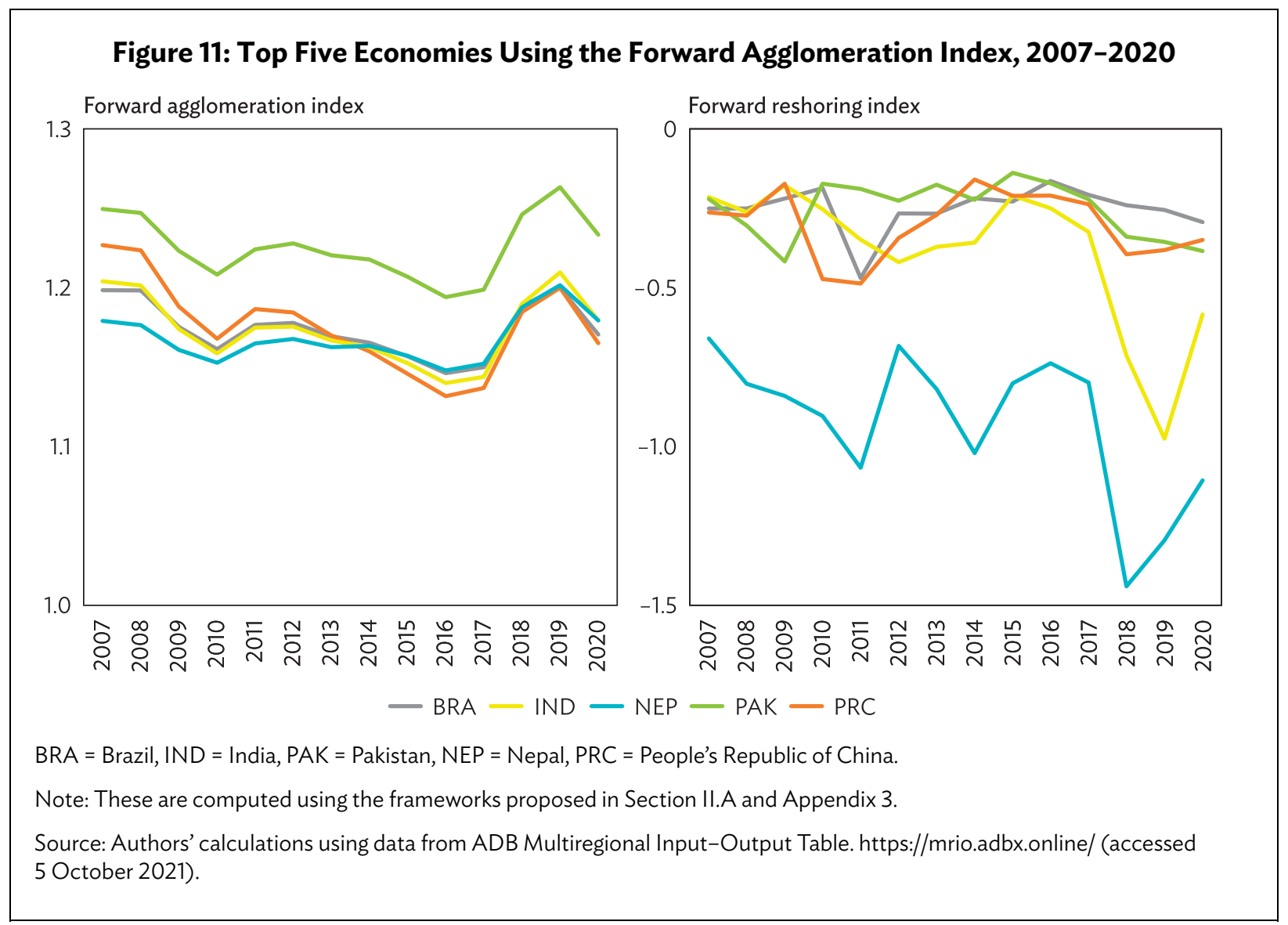

\section{CONCLUSIONS}

The past decades have shown increasing interconnectedness between sectors across the globe. The rise of GVCs, which allowed for fragmentation of production processes, increased the reliance of different economies on a larger global market. In the recent years, however, evidence shows the start of slowbalization, marked by slowdown of cross-border movement of goods and services (D'Urbino 2019, Titievskaia et al. 2020). In this context, the role of the domestic sectors rises in importance.

The domestic sectors contribute indirectly to GVC activities, either by providing intermediate inputs to sectors directly engaging in GVC activities, or by using products of GVC sectors as intermediate inputs (Mercer-Blackman, Foronda, and Mariasingham 2017; Beverelli et al. 2015). This paper contributes to the existing literature by developing a measure of domestic linkages using the concept of agglomeration. It extends the location concept central in the agglomeration literature to the global economy. Specifically, the backward and forward agglomeration indexes measure the extent to which the domestic economy sectors source and/or absorb value-added from other sectors. The base agglomeration indexes measure the concentration of value added in the domestic market. The study further refined the agglomeration indexes to account for concentration of activities within the domestic sectors. Together, the indexes attempt to provide a picture of how the domestic sectors contribute to the global economy. 
Trends using the agglomeration indexes reveal heterogeneity in economy-level agglomeration. At a sector level, the light manufacturing sector shows high backward agglomeration across economies. This provides evidence of the increasing role of the domestic sectors as sources of inputs for the light manufacturing sector. In terms of GVCs, the paper shows preliminary evidence of a negative correlation between agglomeration and GVC participation when an economy has low backward and/or forward agglomeration. Economies with high backward or forward agglomeration, however, exhibit a positive relationship with GVC participation. High agglomeration enables economies to channel gains from GVC participation through strong domestic linkages, which may create further incentives to participate in GVCs.

Accounting for concentration of activities within the domestic sector matters in measuring agglomeration. Economies dominated by a few sectors will exhibit DVA concentration, limiting the breadth of domestic linkages to a few sectors. Thus, incorporating concentration of activities within the domestic sectors may result in a change in agglomeration class.

In gauging the performance of the agglomeration indexes as measurement of an economy's reshoring activities, the indexes are compared with the modified Kearney reshoring index (MKRI). Estimates show that the agglomeration indexes generate results consistent with the existing index and perform well in measuring the reshoring activities of an economy. Differences between the agglomeration indexes and the MKRI highlight the advantage of the agglomeration indexes. The use of a value-added approach for the agglomeration indexes allows for a more accurate measure of domestic concentration of sources of inputs. This sheds light on what the agglomeration indexes can offer relative to existing measures.

From a policy standpoint, the agglomeration indexes presented in this paper can be employed in determining which sectors to prioritize when setting national agenda. High agglomeration, especially through forward linkages, will allow economies to maximize gains in participating in GVC-related activities. This, in turn, is likely to have implications for overall growth. While this is not explored in the current paper, it presents a rich area for further study. 


\section{APPENDIX 1: ADB MULTIREGIONAL INPUT-OUTPUT TABLE STRUCTURE}

The primary data source used throughout is the Asian Development Bank (ADB) multiregional input-output table (MRIOT), which extends tables sourced from the World Input-Output Database (WIOD) by adding 19 economies from Asia and the Pacific region to WIOD's 43 economies (Timmer et al. 2015). A residual "rest of the world" entity accounts for all other economies.

The structure of the ADB MRIOT is given in Figure A1. Information can be classified into four major matrices. Matrix $Z_{G N \times G N}$ contains information on intermediate use, while $V a_{6 \times G N}$ contains information on (i) taxes less subsidies on products; (ii) cost, insurance and freight (CIF) and free on board (FOB) adjustments on exports; (iii) direct purchases abroad by residents; (iv) purchases on the domestic territory by nonresidents; ( $v$ ) value added at basic prices; and ( $v i$ ) international transport margins. Meanwhile, information on final demand is provided in matrix $y_{G N \times 5 N}$. Lastly, gross output is defined by the vector $x_{G N \times 1}$. All of these are used to compute the technical coefficient matrix $A=Z \hat{x}^{-1}$ and the Leontief inverse $B=(I-A)^{-1}$, both of which are used to compute equations 1 and 2 .

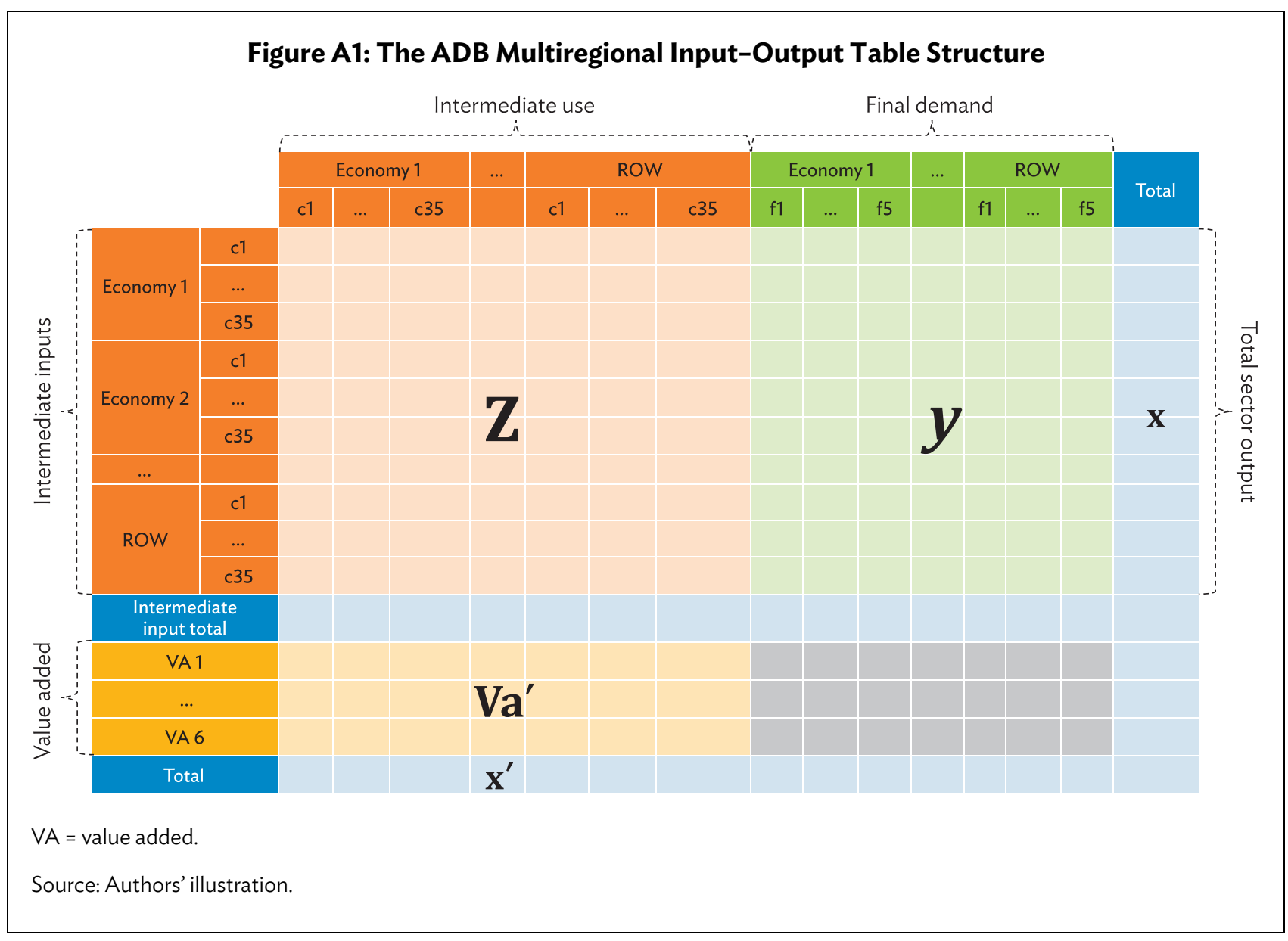

A description of sectors used in the ADB MRIOT are provided in Table A1. 
Table A1: Sector Descriptions of the ADB Multiregional Input-Output Table

\begin{tabular}{|c|c|}
\hline Code & Sector Description \\
\hline 1 & Agriculture, hunting, forestry, and fishing \\
\hline 2 & Mining and quarrying \\
\hline 3 & Food, beverages, and tobacco \\
\hline 4 & Textiles and textile products \\
\hline 5 & Leather, leather products, and footwear \\
\hline 6 & Wood and products of wood and cork \\
\hline 7 & Pulp, paper, paper products, printing, and publishing \\
\hline 8 & Coke, refined petroleum, and nuclear fuel \\
\hline 9 & Chemicals and chemical products \\
\hline 10 & Rubber and plastics \\
\hline 11 & Other nonmetallic minerals \\
\hline 12 & Basic metals and fabricated metal \\
\hline 13 & Machinery, not elsewhere classified \\
\hline 14 & Electrical and optical equipment \\
\hline 15 & Transport equipment \\
\hline 16 & Manufacturing, not elsewhere classified; recycling \\
\hline 17 & Electricity, gas, and water supply \\
\hline 18 & Construction \\
\hline 19 & Sale, maintenance, and repair of motor vehicles and motorcycles; retail sale of fuel \\
\hline 20 & Wholesale trade and commission trade, except of motor vehicles and motorcycles \\
\hline 21 & Retail trade, except of motor vehicles and motorcycles; repair of household goods \\
\hline 22 & Hotels and restaurants \\
\hline 23 & Inland transport \\
\hline 24 & Water transport \\
\hline 25 & Air transport \\
\hline 26 & Other supporting and auxiliary transport activities; activities of travel agencies \\
\hline 27 & Post and telecommunications \\
\hline 28 & Financial intermediation \\
\hline 29 & Real estate activities \\
\hline 30 & Renting of machinery and equipment and other business activities \\
\hline 31 & Public administration and defense; compulsory social security \\
\hline 32 & Education \\
\hline 33 & Health and social work \\
\hline 34 & Other community, social, and personal services \\
\hline 35 & Private households with employed persons \\
\hline
\end{tabular}

Source: ADB Multiregional Input-Output Table. https://mrio.adbx.online/. 


\section{APPENDIX 2: GLOBAL VALUE CHAIN PARTICIPATION AND AGGLOMERATION INDEXES}

Table A2.1: Regression Results using Backward Agglomeration

\begin{tabular}{|c|c|c|c|}
\hline & \multicolumn{3}{|c|}{ Dependent variable } \\
\hline & \multicolumn{3}{|c|}{ Log of Trade-based GVC Participation } \\
\hline & $\begin{array}{l}\text { OLS } \\
(1)\end{array}$ & $\begin{array}{l}\text { Fixed } \\
(2)\end{array}$ & $\begin{array}{c}\text { Random } \\
\text { (3) }\end{array}$ \\
\hline Log of Backward agglomeration $(t-1)$ & $\begin{array}{r}-0.090^{* * *} \\
(0.002)\end{array}$ & $\begin{array}{c}-0.011^{* * *} \\
(0.002)\end{array}$ & $\begin{array}{l}-0.004^{*} \\
(0.002)\end{array}$ \\
\hline 2009 & $\begin{array}{r}-0.103^{* * *} \\
(0.016)\end{array}$ & $\begin{array}{r}-0.093^{* * *} \\
(0.009)\end{array}$ & $\begin{array}{r}-0.092^{* * *} \\
(0.009)\end{array}$ \\
\hline 2010 & $\begin{array}{r}-0.056^{* * *} \\
(0.016)\end{array}$ & $\begin{array}{r}-0.051^{* * *} \\
(0.009)\end{array}$ & $\begin{array}{r}-0.050^{* * *} \\
(0.009)\end{array}$ \\
\hline 2011 & $\begin{array}{r}-0.011 \\
(0.015)\end{array}$ & $\begin{array}{c}-0.004 \\
(0.009)\end{array}$ & $\begin{array}{r}-0.003 \\
(0.008)\end{array}$ \\
\hline 2012 & $\begin{array}{r}-0.029^{*} \\
(0.016)\end{array}$ & $\begin{array}{l}-0.014^{*} \\
(0.009)\end{array}$ & $\begin{array}{r}-0.013 \\
(0.008)\end{array}$ \\
\hline 2013 & $\begin{array}{r}-0.016 \\
(0.016)\end{array}$ & $\begin{array}{r}-0.011 \\
(0.009)\end{array}$ & $\begin{array}{r}-0.010 \\
(0.008)\end{array}$ \\
\hline 2014 & $\begin{array}{r}-0.047^{* * *} \\
(0.015)\end{array}$ & $\begin{array}{r}-0.034^{* * *} \\
(0.009)\end{array}$ & $\begin{array}{r}-0.032^{* * *} \\
(0.008)\end{array}$ \\
\hline 2015 & $\begin{array}{r}-0.048^{* * *} \\
(0.016)\end{array}$ & $\begin{array}{r}-0.033^{* * *} \\
(0.009)\end{array}$ & $\begin{array}{r}-0.032^{* * *} \\
(0.008)\end{array}$ \\
\hline 2016 & $\begin{array}{r}-0.034^{* *} \\
(0.015)\end{array}$ & $\begin{array}{l}-0.017^{* *} \\
(0.009)\end{array}$ & $\begin{array}{l}-0.016^{*} \\
(0.008)\end{array}$ \\
\hline 2017 & $\begin{array}{l}-0.007 \\
(0.015)\end{array}$ & $\begin{array}{r}0.013 \\
(0.008)\end{array}$ & $\begin{array}{r}0.014^{*} \\
(0.008)\end{array}$ \\
\hline 2018 & $\begin{array}{c}0.061^{* * *} \\
(0.015)\end{array}$ & $\begin{array}{c}0.084^{* * *} \\
(0.008)\end{array}$ & $\begin{array}{c}0.086^{* * *} \\
(0.008)\end{array}$ \\
\hline 2019 & $\begin{array}{l}-0.001 \\
(0.015)\end{array}$ & $\begin{array}{c}0.024^{* * *} \\
(0.008)\end{array}$ & $\begin{array}{l}0.025^{* * *} \\
(0.008)\end{array}$ \\
\hline 2020 & $\begin{array}{r}-0.100^{* * *} \\
(0.015)\end{array}$ & $\begin{array}{r}-0.031^{* * *} \\
(0.009)\end{array}$ & $\begin{array}{r}-0.025^{* * *} \\
(0.009)\end{array}$ \\
\hline Low Income & $\begin{array}{r}-0.183^{* * *} \\
(0.024)\end{array}$ & $\begin{array}{r}-0.245^{* * *} \\
(0.072)\end{array}$ & \\
\hline Lower middle income & $\begin{array}{r}-0.169^{* * *} \\
(0.008)\end{array}$ & $\begin{array}{r}-0.230^{* * *} \\
(0.024)\end{array}$ & \\
\hline Upper middle income & $\begin{array}{r}-0.148^{* * *} \\
(0.008)\end{array}$ & $\begin{array}{r}-0.187^{* * *} \\
(0.023)\end{array}$ & \\
\hline Constant & $\begin{array}{r}-0.896^{* * *} \\
(0.011)\end{array}$ & $\begin{array}{r}-0.859^{* * *} \\
(0.013)\end{array}$ & \\
\hline Observations & 26,405 & 26,405 & 26,405 \\
\hline$R^{2}$ & 0.091 & 0.028 & 0.024 \\
\hline Adjusted $R^{2}$ & 0.090 & 0.028 & -0.062 \\
\hline
\end{tabular}

$\mathrm{GVC}=$ global value chain, $\mathrm{OLS}=$ ordinary least squares.

Note: "Random" refers to random effects regression, while "Fixed" denotes fixed effects regression. Standard errors in parentheses. ${ }^{*}=p<.10,{ }^{* *}=p<.05,{ }^{* * *}=p<.01$.

Source: Authors' calculations using data from ADB Multiregional Input-Output Table. https://mrio.adbx.online/ (accessed 21 September 2021). 


\section{APPENDIX 3: MODIFIED KEARNEY RESHORING INDEX}

The Kearney reshoring index measures offshoring activities by looking at the year-on-year change of an economy's imports ratio for a specific product (Kearney 2021). The reshoring index was redefined for it to be comparable with the agglomeration indexes in terms of data and framework, but nevertheless holds true to its definition. The definition of the reshoring index can be translated as the change in total imports over domestic gross output.

$$
\text { Reshoring Index } \left.\text { I }_{t-1}-I R_{t}\right) \times 100=\left(\frac{\text { imports }_{t-1}}{\text { domestic output }_{t-1}}-\frac{\text { imports }_{t}}{\text { domestic output }_{t}}\right) \times 100
$$

The index is translated to eliminate dependence from the level of imports over domestic gross output of the previous year through the use of a multiplier, which shows the increase in imported inputs with a change in final demand. This becomes comparable with the agglomeration index since an increase in imported inputs also mean an increase in interregional linkages.

The backward and forward measures of the modified Kearney reshoring index (MKRI) depend on the linkage measure multiplied to the imports ratio. The backward MKRI considers the upstream sectors, while the forward MKRI considers the downstream sectors. The imports ratio provides an insight regarding the offshoring activities of a sector's inputs and is defined as the total imported inputs divided by total domestic inputs, wherein total imported inputs $M^{D}$ is the sum of offshore intermediate inputs of a sector and total domestic inputs $P^{D}$ is the sum of domestic intermediate inputs. Suppose there are three economies (i.e., $R=D, E, F$ ) and each economy has three sectors (i.e., $i=1,2,3$ ), the imports ratio of sector $j$ of the domestic economy $D$ is defined as follows, where $Z$ is the interindustry transactions matrix:

$$
I R_{j}^{D}=\frac{M^{D}}{P^{D}}=\frac{\sum_{R=E}^{F} \sum_{i=1}^{3} Z_{i j}^{R}}{\sum_{i=1}^{3} Z_{i j}^{D}}
$$

The backward MKRI for sector $j$ of the domestic economy $D$ is the sum of the product of the import ratios and the backward linkages:

$$
M(b)_{j}=\sum_{i=1}^{3}\left(\frac{\Delta \text { Domestic Total Output }}{\Delta \text { Final Demand }}{ }_{j}^{D} \times \frac{\text { Total Imported Inputs }_{j}^{D}}{\text { Total Domestic Inputs }_{j}^{D}}\right)_{i}
$$

In matrix notation, it is computed by post-multiplying the diagonal matrix of the imports ratio to the domestic Leontief inverse matrix. The $\boldsymbol{M}(b)_{j}$ gives the trade-off between imported and domestic inputs required to produce the additional output needed to satisfy a $\$ 1$ increase in final demand for the domestic sector.

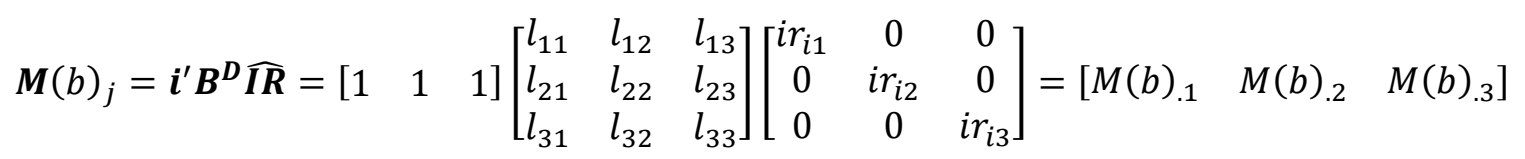


Furthermore, the forward MKRI for sector $i$ of the domestic economy $D$ is the sum of the product of the imports ratio and the forward linkages:

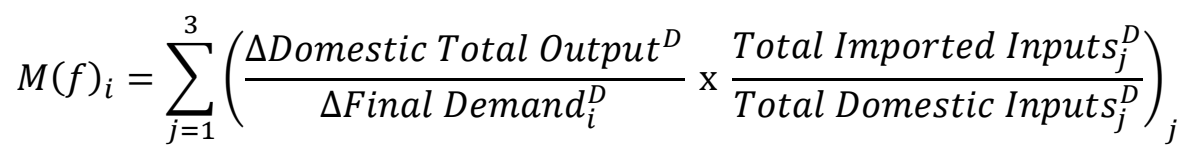

In matrix notation, it is computed by post-multiplying the diagonal matrix of the import ratio to the domestic Ghosh inverse matrix. The $\boldsymbol{M}(f)_{i}$ gives the trade-off between imported and domestic inputs required to satisfy the additional inputs from the domestic sector needed by the other sectors in the economy given a $\$ 1$ increase in the primary input of the domestic sector.

$$
\boldsymbol{M}(f)_{i}=\boldsymbol{G}^{\boldsymbol{D}} \boldsymbol{i} \widehat{\boldsymbol{I R}}=\left[\begin{array}{lll}
g_{11} & g_{12} & g_{13} \\
g_{21} & g_{22} & g_{23} \\
g_{31} & g_{32} & g_{33}
\end{array}\right]\left[\begin{array}{l}
1 \\
1 \\
1
\end{array}\right]\left[\begin{array}{ccc}
i r_{i 1} & 0 & 0 \\
0 & i r_{i 2} & 0 \\
0 & 0 & i r_{i 3}
\end{array}\right]=\left[\begin{array}{lll}
M(f)_{1} . & M(f)_{2 .} & M(f)_{3 .}
\end{array}\right]
$$




\section{REFERENCES}

Bartelme, Dominick, and Yuriy Gorodnichenko. 2015. "Linkages and Economic Development." NBER Working Paper No. 21251. National Bureau of Economic Research, Cambridge, MA.

Bernard, Andrew B., J. Bradford Jensen, Stephen J. Redding, and Peter K. Schott. 2007. "Firms in International Trade." Journal of Economic Perspectives 21 (3): 105-30. doi: 10.1257/jep.21.3.105.

Beverelli, Cosimo, Robert B. Koopman, Victor Kümmritz, and Simon Neumueller. 2015. "Domestic Foundations of Global Value Chains." https://dx.doi.org/10.2139/ssrn.2708980.

Borin, Alessandro, and Michele Mancini. 2019. "Measuring What Matters in Global Value Chains and Value-Added Trade.” Policy Research Working Paper No. 8804. World Bank, Washington, DC.

D'Urbino, Luca. 2019. “The Steam Has Gone out of Globalisation.” The Economist, January 24.

Feldman, Maryann P. 1999. "The New Economics of Innovation, Spillovers and Agglomeration: Areview of Empirical Studies." Economics of Innovation and New Technology 8 (1-2): 5-25. doi: $10.1080 / 10438599900000002$.

Fujita, Masahisa, and Jacques-François Thisse. 1996. "Economics of Agglomeration." Journal of the Japanese and International Economies 10 (4): 339-78. doi: https://doi.org/10.1006/jjie.1996.0021.

Giuseppina, Talamo, and Sabatino Michele. 2018. "Re-Shoring and Resilience in Italy During and after the Crisis." American Journal of Industrial and Business Management 8 (5): 1172-96.

Han, Wei, Ying Zhang, Jianming Cai, and Enpu Ma. 2019. "Does Urban Industrial Agglomeration Lead to the Improvement of Land Use Efficiency in China? An Empirical Study from a Spatial Perspective." Sustainability 11 (4). doi: 10.3390/su11040986.

Jones, Charles I. 2011. "Intermediate Goods and Weak Links in the Theory of Economic Development." American Economic Journal: Macroeconomics 3 (2): 1-28. doi: 10.1257/mac.3.2.1.

Kearney. 2021. Global Pandemic Roils 2020 Reshoring Index, Shifting Focus from Reshoring to RightShoring. Chicago, IL.

Koenig, Pamina. 2009. "Agglomeration and the Export Decisions of French Firms." Journal of Urban Economics 66 (3): 186-95.

Koopman, Robert, Zhi Wang, and Shang-Jin Wei. 2008. "How Much of Chinese Exports Is Really Made in China? Assessing Domestic Value-Added When Processing Trade Is Pervasive." NBER Working Paper Series No. 14109. National Bureau of Economic Research, Cambridge, MA.

Krugman, Paul, and Anthony J. Venables. 1996. “Integration, Specialization, and Adjustment." European Economic Review 40 (3): 959-67.

Marshall, Alfred. 1920. Principles of Economics, an Introductory Volume. 8th ed. London: Macmillan and Co. 
Mercer-Blackman, Valerie, Amador Foronda, and Mahinthan J. Mariasingham. 2017. "Using InputOutput Analysis Framework to Explain Economic Diversification and Structural Transformation in Bangladesh." ADB Economics Working Paper Series No. 513. Asian Development Bank, Manila.

Miller, Ronald E., and Peter D. Blair. 2009. Input-Output Analysis: Foundations and Extensions. Cambridge, UK: Cambridge University Press.

OECD. 2013. Interconnected Economies. Paris: OECD Publishing.

Pegoraro, Diletta, Lisa De Propris, and Agnieszka Chidlow. 2020. "De-Globalisation, Value Chains and Reshoring." In Industry 4.0 and Regional Transformations, edited by Lisa De Propris and David Bailey, 152-75. London: Routledge.

Tang, Heiwai, Fei Wang, and Zhi Wang. 2020. "Domestic Segment of Global Value Chains in China under State Capitalism涴.” Journal of Comparative Economics 48 (4): 797-821.

Timmer, Marcel P., Erik Dietzenbacher, Bart Los, Robert Stehrer, and Gaaitzen J. de Vries. 2015. “An Illustrated User Guide to the World Input-Output Database: The Case of Global Automotive Production." Review of International Economics 23 (3): 575-605.

Titievskaia, Jana, Vadim Kononenko, Cecilia Navarra, Carla Stamegna, and Klemen Zumer. 2020. Slowing Down or Changing Track? Understanding the Dynamics of 'Slowbalisation'. Brussels: European Union.

Venables, Anthony J. 1996. "Localization of Industry and Trade Performance." Oxford Review of Economic Policy 12 (3): 52-60.

Wang, Zhi, Shang-Jin Wei, Xinding Yu, and Kunfu Zhu. 2017. "Measures of Participation in Global Value Chains and Global Business Cycles." NBER Working Paper Series No. 23222. National Bureau of Economic Research, Cambridge, MA. 


\section{Measuring Localization in the Age of Economic Globalization}

The past 2 decades have witnessed the growing importance of global value chains (GVCs), as production processes have become fragmented and shared across economies. This paper adopts the concept of agglomeration in the context of GVCs by exploring the clustering of economic activities in domestic sectors amid a highly interconnected global economy. It develops an agglomeration index that measures the strength of an economy's domestic linkages, using ADB's multiregional input-output table. It examines the scale of value-added sourced from and/or absorbed into domestic economy sectors given the production of final goods in other sectors.

\section{About the Asian Development Bank}

ADB is committed to achieving a prosperous, inclusive, resilient, and sustainable Asia and the Pacific, while sustaining its efforts to eradicate extreme poverty. Established in 1966, it is owned by 68 members -49 from the region. Its main instruments for helping its developing member countries are policy dialogue, loans, equity investments, guarantees, grants, and technical assistance. 